NBER WORKING PAPER SERIES

MINORITY TURNOUT AND REPRESENTATION UNDER CUMULATIVE VOTING. AN EXPERIMENT.

\author{
Alessandra Casella \\ Jeffrey Guo \\ Michelle Jiang \\ Working Paper 28674 \\ http://www.nber.org/papers/w28674 \\ NATIONAL BUREAU OF ECONOMIC RESEARCH \\ 1050 Massachusetts Avenue \\ Cambridge, MA 02138 \\ April 2021
}

We acknowledge with gratitude the financial support of the Columbia University Program for Economic Research and the Columbia Experimental Lab for the Social Sciences. The views expressed herein are those of the authors and do not necessarily reflect the views of the National Bureau of Economic Research.

NBER working papers are circulated for discussion and comment purposes. They have not been peer-reviewed or been subject to the review by the NBER Board of Directors that accompanies official NBER publications.

(C) 2021 by Alessandra Casella, Jeffrey Guo, and Michelle Jiang. All rights reserved. Short sections of text, not to exceed two paragraphs, may be quoted without explicit permission provided that full credit, including $\odot$ notice, is given to the source. 
Minority Turnout and Representation under Cumulative Voting. An Experiment. Alessandra Casella, Jeffrey Guo, and Michelle Jiang

NBER Working Paper No. 28674

April 2021

JEL No. C92,D7,D72,K16

\section{ABSTRACT}

Under majoritarian election systems, securing participation and representation of minorities remains an open problem, made salient in the US by its history of voter suppression. One remedy recommended by the courts is Cumulative Voting (CV): each voter has as many votes as open positions and can cumulate votes on as few candidates as desired. Theory predicts that CV encourages the minority to overcome obstacles to voting: although each voter is treated equally, $\mathrm{CV}$ increases minority's turnout relative to the majority, and the minority's share of seats won. A lab experiment based on a costly voting design strongly supports both predictions.

Alessandra Casella

Department of Economics

Columbia University

420 West 118 Street

New York, NY 10027

and NBER

ac186@columbia.edu

Jeffrey Guo

420 West 118th Street

Department of Economics

Columbia University

New York, NY 10027

USA

jeffrey.guo@columbia.edu
Michelle Jiang

420 West 118th Street

Department of Economics

Columbia University

New York, NY 10027

michelle.jiang@columbia.edu

A data appendix is available at http://www.nber.org/data-appendix/w28674 
"And so the world watches America - the only great power in history made up of people from every corner of the planet, comprising every race and faith and cultural practice - to see if our experiment in democracy can work. To see if we can do what no other nation has ever done. To see if we can actually live up to the meaning of our creed. The jury's still out." (Obama, 2020, p. xvi).

\section{Introduction}

The fragility of American democracy, rooted historically in slavery, manifests itself in persistent efforts to disenfranchise racial and linguistic minorities, Black Americans first and foremost. The watershed passing of the Voting Rights Act (VRA) in 1965 aimed to remedy the unequal access to the polls. In 2013, however, in Shelby County v. Holder, the Court voided the VRA formula used to identify jurisdictions subject to federal oversight of their electoral rules, effectively blocking the reach of the VRA. Political participation and representation of minorities remain fiercely debated. ${ }^{1}$

Under America's majoritarian electoral system, granting representation to minority groups is difficult. If voters cast a single vote for a single candidate, the majority, no matter how slender, is guaranteed victory. The exact boundaries of the political district dictate the outcome and are predictable ground for partisan fights. ${ }^{2}$ A possible remedy is the creation of larger, less arbitrary, multi-member districts, where multiple positions are at stake. Per se, multi-member districts do not alleviate the mechanical control granted to the majority; they do however make it possible to adopt alternative voting systems that weaken such control. As noted already by Charles Dodgson (aka Lewis Carroll) in 1884, the core idea is to vary the number of votes that voters can cast for each candidate. Cumulative Voting $(\mathrm{CV})$ is one such alternative system.

Under CV, each voter has as many votes as there are open seats, and the candidates with more votes win, as under simple plurality. However, each voter is allowed to distribute the votes freely among any number of candidates. CV treats every voter equally; yet, a cohesive minority can ensure itself some victories by cumulating its vote. CV was used for more than 100 years, from 1870 to

\footnotetext{
${ }^{1}$ For a brief panoramic summary of voter suppression in the US and the role of the VRA, see Grofman et al. 1992.

${ }^{2}$ The creation of majority-minority districts is problematic on many fronts and was deemed unconstitutional by the Supreme Court (Shaw v. Reno, 1993, and subsequent decisions).
} 
1980, to elect representatives to the Illinois State House and is the rule now in tens of local jurisdictions, often as the remedy imposed by the courts in response to voting rights litigation. Outside local politics, it is used to elect corporate boards in approximately $10 \%$ of S\&P 500 companies. ${ }^{3}$

Empirically, CV correlates with an increase in the number of elected minority representatives (Brockington et al. 1998, Bowler et al., 2003), and in the public goods provided to minority communities (Pildes and Donoghue, 1995). In addition, its use appears to increase minority participation in the political system (Bowler et al., 2001). Evaluating these empirical results, however, is complicated by the non-random adoption of CV: CV typically follows voting rights litigation, indicating heightened sensitivity to minority representation and stronger minority involvement. The historical evidence then must be accompanied by experimental testing. It is such testing that we conduct in this paper.

Higher minority turnout under CV is usually attributed to more optimistic prospects of affecting the electoral outcome. In the lab, the hypothesis maps directly into an experiment where payoffs depend on one's own group achieving electoral success but voting is individually costly. Do participants, particularly participants on the minority side, overcome those costs more often when votes can be cumulated?

The costly voting model we implement is the classic tool for studying instrumental voting (Riker and Ordeshook 1968, Palfrey and Rosenthal 1983, Ledyard 1984). The model does not explain the level of turnout observed in large elections, but captures well the comparative statics properties of different elections: turnout is predicted to increase when elections are closer, when they are more salient, when voting costs are lower, when the electorate is smaller. It is this type of comparative effect that interests us: does minority turnout increase when the voting rule changes to $\mathrm{CV}$ ?

We run different experimental treatments, comparing standard one-voteper-open-seat voting and CV, and varying both the number of seats and the relative size of the minority. For all our parametrizations, theory suggests that CV should increase the minority's turnout relative to the majority's, as well as the fraction of seats won by minority candidates. Both predictions are satisfied in every case. The experiment confirms CV's potential to increase both the

\footnotetext{
${ }^{3}$ See Bowler et al. 2003 for a short history of CV. Other useful sources are Bowler et al. 1999, Engstrom 2010, Pildes and Donoghue 1995. For a strong defense of CV, see Guinier 1994. Updated information on the current use of CV is reported in fairvote.org.
} 
minority's turnout and its electoral success.

Previous laboratory experiments on CV (Gerber et al., 1998, and Cooper and Zillante, 2012), focus on the coordination problem it poses and ignore the question of turnout. We take the opposite approach. Historically, CV's coordination problem is deferred to the parties' leadership and addressed primarily through the leaders' choice of the number of party candidates. ${ }^{4}$ Once the correct number of candidates is chosen, distributing votes equally is an easy default for voters and often, as in the cases we study, maximizes electoral success. ${ }^{5}$ Inspired by such experiences, we test CV by presenting the experimental subjects with an exogenously given, theoretically optimal, number of candidates; if they decide to vote, their votes are shared equally over their party's candidates. Our focus is fully on the turnout decision. Closer to us, then, are experiments that concentrate on turnout, and especially on relative turnout for groups of different sizes (Levine and Palfrey, 2007). Because CV is an example of "semi-proportional" voting rules-rules that approach proportional representation without a proportional electoral system-particularly relevant is the experiment in Herrera et al. (2014), comparing turnout under single-winner majoritarian and proportional elections, and qualifying the commonly held belief that turnout is higher in the latter case.

The American electoral system has been fashioned by its British roots and by the founders' resolution to hamper the emergence of factions. Both have resulted in opposition to proportional representation. Electoral rules like CV have the potential to afford representation to groups that often do share common goals but can be confined to permanent minority status by majoritarian voting. Such rules can do so without the rigidity and arbitrariness of majority-minority single member districts, or of quota systems. They deserve more study.

\section{Base Model}

An electorate of $N$ potential voters selects $K>1$ representatives for a commission. Each position is identical to the others, and all positions are simultaneously decided in the election. The $N$ voters are divided into two parties: $\mathrm{M}$,

\footnotetext{
${ }^{4}$ The literature is rife with colorful examples of leaders' fast learning after mistakenly nominating too many or too few candidates (Bowler et al., 1999, Sawyer and MacRae, 1962, Pildes and Donoghue, 1995).

${ }^{5}$ Sawyer and MacRae (1962) and Goldburg (1994) document that equal spreading of votes over all party candidates was the norm during the long experience of CV in the Illinois State House, where behavior likely converged to incorporate CV's lessons.
} 
the majority party with $M$ members, and $\mathrm{m}$, the minority party with $m<M$ members, where $M+m=N$. Parties are led by party leaders whose role is to propose the party's list of candidates.

Party leaders and voters share the same objective: to maximize the number of positions won by their party. The utility derived from one's party winning $k$ positions is $u(k)$, increasing in $k$. We denote by $V$ the value of controlling all positions and assume $u(k)=(k / K) V$. Linearity captures the simple objective posited above and simplifies both the lab implementation and the theoretical analysis. We adopt it on substantive grounds as well: empirically, any "place at the table" has value. The assumption mirrors an exercise of committee power that is proportional to the number of seats a party has won.

Each voter has $K$ votes, and the $K$ candidates with most votes are elected. If there are ties, after the highest voted candidates are elected, the remaining open positions are filled by selecting winners randomly among the tied candidates. We call $x_{p}$ the profiles of votes cast by members of party $p$, where $x_{i p}^{k}$ is the number of votes cast by voter $i \in p$ for candidate $k$, and $x_{i p}$ the vector of all votes cast by $i$.

We study two electoral systems, multi-seat plurality (MP), and cumulative voting $(\mathrm{CV})$. Under MP, each voter is constrained to one vote for each candidate: $x_{i p}^{k}=1$ for all $i, k$, and $p$, and each party nominates $K$ candidates. Under CV, each voter can distribute the $K$ votes in any manner the voter desires, as long as the overall budget of $K$ votes is satisfied: $\sum_{k} x_{i p}^{k}=K$. The possibility of cumulating votes creates a coordination problem that party leaders help address by selecting the number of candidates, $G$ for the majority party, and $g$ for the minority party. In line with historical experience ${ }^{6}$, we allow for fractional votes, but voters, candidates, and positions are constrained to be integers.

The game has two stages. In the first stage, party leaders announce the party list; in the second stage, voters distribute their votes over the party candidates. We focus on equilibria in weakly undominated strategies where voters cast all their votes and cast votes on party candidates only. Under MP, each voter casts one vote for each party candidate. Under CV, the equilibrium is a pair of vote profiles $\left\{x_{\mathrm{M}}(G, g), x_{\mathrm{m}}(G, g)\right\}$ and a pair of party lists $\left\{G\left(x_{\mathrm{M}}, x_{\mathrm{m}}\right), g\left(x_{\mathrm{M}}, x_{\mathrm{m}}\right)\right\}$ such that each party member's votes maximize the number of seats won by the party, given the parties' lists and the other voters' voting choices, and each party list maximizes the number of seats won by the party, given the opposite

\footnotetext{
${ }^{6}$ For example, half votes were allowed in the Illinois State House; half, third, and quarter votes are allowed in the Peoria, IL elections.
} 
party's list and all voters' voting choices.

\subsection{Minority representation without voting costs}

With no reasons to abstain and no leeway in distributing votes, under MP, party $\mathrm{M}$ wins all seats: each $\mathrm{M}$ candidate receives $M$ votes, and each $\mathrm{m}$ candidate receives $m<M$ votes.

CV grants the minority the possibility of winning some seats. Suppose for example that all voters in party $\mathrm{m}$ concentrate all their votes on a single candidate, who thus receives $m K$ votes. The minority candidate is certain to win a seat if there are no more than $K-1$ majority candidates with at least $m K$ votes: the relevant competition is with the weakest of the majority candidates. In turn, if the majority attempts to win all seats, the weakest majority candidate will have most votes when the $M K$ total majority votes are distributed equally among $K$ majority candidates, and each receives $M K / K=M$ votes. Hence the minority can guarantee itself a seat if $m K>M$, or $m>M / K$. This ratio, known as the threshold of exclusion, is a fraction of $M$ : for example, a minority that is half the size of the majority can guarantee itself a seat if the number of open seats is three or more.

How many seats can the minority win? Sawyer and MacRae (1962) provide an elegant early analysis; more recently, practitioners of CV have developed a formula that calculates boundaries on the number of seats that can be won, given $K, M$, and $m .^{7}$ The formula ignores the strategic interaction between the two parties, but the answer it yields can be grounded in a full strategic analysis. We denote by $z$ the number of seats won by party $\mathrm{m}$. As we prove in the appendix:

Proposition 1. In the absence of voting costs, for all $m, M>m$, and $K$, in all equilibria of the voting game:

$$
\begin{aligned}
& z=0 \quad \text { if } m<M / K \\
& z \in\left(\frac{K m-M}{M+m}, \frac{K m+m}{M+m}\right) \quad \text { if } m>M / K \text { and } \frac{K m-M}{M+m} \notin \mathbb{Z}_{+} \\
& z=\left\{\begin{array}{ll}
\frac{K m-M}{M+m} & \text { with prob } m /(M+m) \\
\frac{K m+m}{M+m} & \text { with prob } M /(M+m)
\end{array} \text { if } m \geq M / K \text { and } \frac{K m-M}{M+m} \in \mathbb{Z}_{+}\right.
\end{aligned}
$$

\footnotetext{
${ }^{7} \mathrm{CV}$-calculators can be found online. See, for example, sbbizlaw.com, or Wikipedia (https://en.wikipedia.org/wiki/Cumulative_voting).
} 
Because $(K m+m) /(M+m)-(K m-M) /(M+m)=1$, if $\frac{K m-M}{M+m}$ is not an integer, there exists a unique integer value of $z$ in the relevant interval; if $\frac{K m-M}{M+m}$ is an integer, then $\frac{K m+m}{M+m}$ is one as well.

The result follows from two main reasons. First, because voters and leaders share a common goal, we can simplify the game to a two-player game, with the two party leaders directly controlling the distribution of the votes over the party candidates. Second, the linearity of $u(k)$ renders the game constant-sum. As a result, although there are multiple equilibria, all equilibria must yield the same payoffs the players can guarantee themselves, i.e., the maximin payoffs. Extending the reasoning described above then yields the proposition. ${ }^{8}$

In the absence of voting costs, $\mathrm{CV}$ makes it possible for the minority to win some seats, in contrast to the monopoly of power granted to the majority under MP. But in realistic applications a crucial question is turnout. We extend the model to include voting costs.

\section{$3 \quad$ Voting costs}

Suppose now that each voter $i$ faces a cost of voting $c_{i}$, drawn randomly and independently across voters from a common distribution $F(c)$ with support $[\underline{c}, \bar{c}]$. Realized costs are private information, but the distribution $F(c)$ is common knowledge and does not depend on party affiliation. The cost $c_{i}$ represents the cost of going to the polls and is independent of the number of votes cast. A voter whose party wins $k$ positions has utility $U_{i}(k)$, given by:

$$
U_{i}(k)= \begin{cases}u(k)-c_{i} & \text { if voter } i \text { voted } \\ u(k) & \text { if voter } i \text { abstained }\end{cases}
$$

\subsection{Multi-winner plurality (MP)}

Under MP, voters who have turned out cast a single vote for each of the party's $K$ candidates. Although multiple positions are in play, the analysis mirrors

\footnotetext{
${ }^{8}$ In the simplest equilibrium, all voters spread their votes equally over their party's candidates. Party candidates are $g=z, G=K-z$ if $m>M / K$ and $\frac{K m-M}{M+m} \notin \mathbb{Z}_{+}$, and $g=(K m+m) /(M+m), G=K-(K m-M) /(M+m)$ if $m \geq M / K$ and $\frac{K m-M}{M+m} \in \mathbb{Z}_{+}$. If $m<M / K, G=K ; g$ is irrelevant since no $\mathrm{m}$ candidate can be elected. Other equilibria exist with different numbers of candidates and unequal divisions of votes, correctly anticipated by the party leaders. All equilibria yield the same $z$. See the appendix.
} 
closely the standard approach to costly voting in single winner elections. ${ }^{9}$

Call $S_{p}$ the number of voters who turn out for party $p$. Each $\mathrm{M}$ candidate receives $S_{\mathrm{M}}$ votes, and each $\mathrm{m}$ candidate receives $S_{\mathrm{m}}$ votes. Thus only three outcomes are possible: either $S_{\mathrm{M}}>S_{\mathrm{m}}$, and all $K$ positions are won by $\mathrm{M}$ candidates; or $S_{\mathrm{M}}<S_{\mathrm{m}}$, and all $K$ positions are won by m candidates; or $S_{\mathrm{M}}=$ $S_{\mathrm{m}}$, and all $K$ positions are tied, with $K$ majority and $K$ minority candidates all having the same number of votes. Under a tie, the $K$ winners are chosen randomly among all tied candidates. We denote by $E u_{T}^{M P}$ the expected utility gain from winning seats under MP in case of a tie. Then:

$$
E u_{T}^{M P}=\sum_{k=0}^{K} \frac{\left(\begin{array}{c}
K \\
k
\end{array}\right)\left(\begin{array}{c}
K \\
K-k
\end{array}\right)}{\left(\begin{array}{c}
2 K \\
K
\end{array}\right)} u(k)=V / 2
$$

where the second equality follows from $u(k)=(k / K) V$.

As in single-winner elections, a voter from party $p$ facing opposite party $p^{\prime}$ must weigh her cost of voting against the expected utility gain from influencing the outcome. Denoting by $S_{-i p}$ the number of voters who turn out in party $p$ ignoring $i$, voter $i$ can influence the outcome either by breaking ties (when $S_{-i p}=S_{p^{\prime}}$; an event with probability denoted by $\pi_{p}^{T}$ ) or by making ties (when $S_{-i p}=S_{p^{\prime}}-1$, with probability $\left.\pi_{p}^{T-1}\right)$. Thus the thresholds $\left\{c_{\mathrm{M}}, c_{\mathrm{m}}\right\}$ solve the system of equations:

$$
\begin{aligned}
c_{\mathrm{m}} & =\left[u(K)-E u_{T}^{M P}\right] \pi_{\mathrm{m}}^{T}+\left[E u_{T}^{M P}-u(0)\right] \pi_{\mathrm{m}}^{T-1}=(V / 2) \pi_{\mathrm{m}} \\
c_{\mathrm{M}} & =\left[u(K)-E u_{T}^{M P}\right] \pi_{\mathrm{M}}^{T}+\left[E u_{T}^{M P}-u(0)\right] \pi_{\mathrm{M}}^{T-1}=(V / 2) \pi_{\mathrm{M}}
\end{aligned}
$$

where $\pi_{p}\left(c_{p}, c_{p^{\prime}}\right)=\pi_{p}^{T}+\pi_{p}^{T-1}$ is the pivotal probability for a voter of party $p$.

Note that the linearity of the utility function implies that the equilibrium equations (1) and (2) do not depend on $K$. The problem is then formally identical to the classic costly voting problem with a single winner and two alternatives. It is well-known, and we leave the expressions for the pivot probabilities to the appendix. Given equilibrium $\left\{c_{\mathrm{m}}, c_{\mathrm{M}}\right\}$, we can derive the probabilities of winning different number of positions. The derivation is straightforward, and again is left to the appendix.

\footnotetext{
${ }^{9}$ Arzumanian and Polborn (2017) study costly voting with multiple candidates but a single winner. Our model is closer to the traditional two-candidate, one-winner set-up, with each party list being the parallel to the party candidate.
} 


\subsection{Cumulative voting (CV)}

With voting costs, the game cannot be reduced to the two party leaders. It now has three stages: a nomination stage, when the leaders choose the number of candidates; a turnout stage, when, after observing privately the realization of the voting cost, each voter decides whether or not to vote; and finally a voting stage, when voters at the polls choose how to cast their votes.

We focus on a semi-symmetric perfect Bayesian equilibrium such that within each party, all voters follow the same strategy. We denote by $x_{-i p}$ the profile of votes cast by voters other than $i$ who turned out and belong to $p$. The equilibrium is a pair of party lists $\{g, G\}$, a pair of cost thresholds $\left\{c_{\mathrm{M}}, c_{\mathrm{m}}\right\}$, and a pair of voting profiles $\left\{x_{\mathrm{M}}, x_{\mathrm{m}}\right\}$ such that: (i) at the voting stage, conditional on voting, voter $i$ in party $p$ sets $x_{i p}\left(G, g, c_{M}, c_{m}, x_{-i p}, x_{p^{\prime}}\right)$ so as to maximize the expected number of positions won by $p$; (ii) at the turnout stage, all $i \in p$ with $c_{i}<c_{p}\left(G, g, c_{p^{\prime}}, x_{M}, x_{m}\right)$ strictly prefer to vote, and all $i \in p$ with $c_{i}>$ $c_{p}\left(G, g, c_{p^{\prime}}, x_{M}, x_{m}\right)$ strictly prefer to abstain; and (iii) at the nomination stage, the two party leaders set $g\left(G, x_{M}, x_{m}, c_{M}, c_{m}\right)$ and $G\left(g, x_{M}, x_{m}, c_{M}, c_{m}\right)$ so as to maximize their party's expected number of positions. ${ }^{10}$

Note that for any positive turnout, if $g<K$, party $\mathrm{M}$ is guaranteed $\min [G, K-g]$ seats, and similarly, if $G<K$, party $\mathrm{m}$ is guaranteed $\min [g, K-G]$ seats. The positions contested are $g+G-K$. It follows that the equilibrium with equal vote spreading and $g=z, G=K-z$, which exists in the absence of voting costs, cannot exist when voting is costly because no position would be contested, and increasing the number of candidates would be weakly dominant for either party. If voting is costly, in all equilibria $G+g>K$.

We discuss the derivation of the equilibrium cost thresholds, and thus turnout, and then present the theory's numerical predictions for a set of parameters that includes those we use in the experiment. In deriving the equilibrium cost thresholds, we conjecture an equilibrium with equal spreading of votes: $x_{i \mathrm{~m}}^{k}=K / g$, $x_{i \mathrm{M}}^{k}=K / G$. We then verify that the conjecture is indeed a best reply for a voter at the polls.

For given $g$ and $G$, equilibrium cost thresholds continue to trade off costs of voting and expected utility gains from influencing the election. As before, a voter can break an existing tie, or can cause a tie, but if the party's candidates are fewer than the number of seats, and the voter casts more than a

\footnotetext{
${ }^{10}$ Note that party leaders influence turnout indirectly through the number of candidates, recalling models of leaders' enforced social norms in voting (Levine and Mattozzi, 2020).
} 
single vote on each, the voter can now move the outcome from a loss to a win of all contested positions. Consider the problem for $i \in \mathrm{M}$. By voting, $i$ breaks a tie if $(K / G) S_{\mathrm{M}-\mathrm{i}}=(K / g) S_{\mathrm{m}}$, or $S_{\mathrm{M}-\mathrm{i}}=S_{\mathrm{m}}(G / g) ; i$ causes a tie if $(K / G)\left(S_{\mathrm{M}-\mathrm{i}}+1\right)=(K / g) S_{\mathrm{m}}$, or $S_{\mathrm{M}-\mathrm{i}}=S_{\mathrm{m}}(G / g)-1$. In addition, voter $i$ can shift $\mathrm{M}$ from losing to winning all contested positions if both $(K / G) S_{\mathrm{M}-\mathrm{i}}<$ $(K / g) S_{\mathrm{m}}$ and $(K / G)\left(S_{\mathrm{M}-\mathrm{i}}+1\right)>(K / g) S_{\mathrm{m}}$, or $S_{\mathrm{M}-\mathrm{i}} \in\left(S_{\mathrm{m}}(G / g)-1, S_{\mathrm{m}}(G / g)\right)$.

Denoting by $\pi_{p}^{W}$ the probability that the votes of a member of party $p$ move party $p$ from losing to winning all contested positions, if $c_{\mathrm{M}} \in(0,1)$ and $G+g>K, c_{\mathrm{M}}$ must solve:

$c_{\mathrm{M}}=\left[u(G)-E u_{T, \mathrm{M}}^{C V}(G, g)\right] \pi_{\mathrm{M}}^{T}+\left[E u_{T, \mathrm{M}}^{C V}(G, g)-u(K-g)\right] \pi_{\mathrm{M}}^{T-1}+[u(G)-u(K-g)] \pi_{\mathrm{M}}^{W}$

where:

$$
E u_{T, \mathrm{M}}^{C V}(G, g)=\sum_{x=0}^{G} u(x)\left(\begin{array}{c}
G \\
x
\end{array}\right)\left(\begin{array}{c}
g \\
K-x
\end{array}\right) /\left(\begin{array}{c}
G+g \\
K
\end{array}\right)=\frac{G}{g+G} V
$$

Or:

$$
c_{\mathrm{M}}=\frac{V(g+G-K)}{K}\left[\frac{G}{g+G} \pi_{\mathrm{M}}^{T}+\frac{g}{g+G} \pi_{\mathrm{M}}^{T-1}+\pi_{\mathrm{M}}^{W}\right]
$$

The problem is analogous for minority voters. The equilibrium condition for an interior threshold $c_{\mathrm{m}}$ is:

$$
c_{\mathrm{m}}=\frac{V(g+G-K)}{K}\left[\frac{g}{g+G} \pi_{\mathrm{m}}^{T}+\frac{G}{g+G} \pi_{\mathrm{m}}^{T-1}+\pi_{\mathrm{m}}^{W}\right]
$$

The pivot probabilities and the probabilities of winning different numbers of position in case of ties can be derived as under MP, taking into account that the number of candidates, in each party, may differ from the number of seats. We leave them to the appendix.

Given (3) and (4), and $x_{i \mathrm{~m}}^{k}=K / g, x_{i \mathrm{M}}^{k}=K / G$, we can find party leaders' optimal choice of $G$ and $g$, and given $G$ and $g$ and (3) and (4), we can verify that $x_{i \mathrm{~m}}^{k}=K / g, x_{i \mathrm{M}}^{k}=K / G$ are indeed best responses. ${ }^{11}$

\footnotetext{
${ }^{11}$ If $G+g=K+1$, equal spreading of votes is a best reply for any $c_{\mathrm{m}}, c_{\mathrm{M}}$. The reason is that both parties must then compete to elect the weakest of their candidates, and when others spread their votes equally, strengthening the weakest party candidate amounts to spreading votes equally as well.
} 

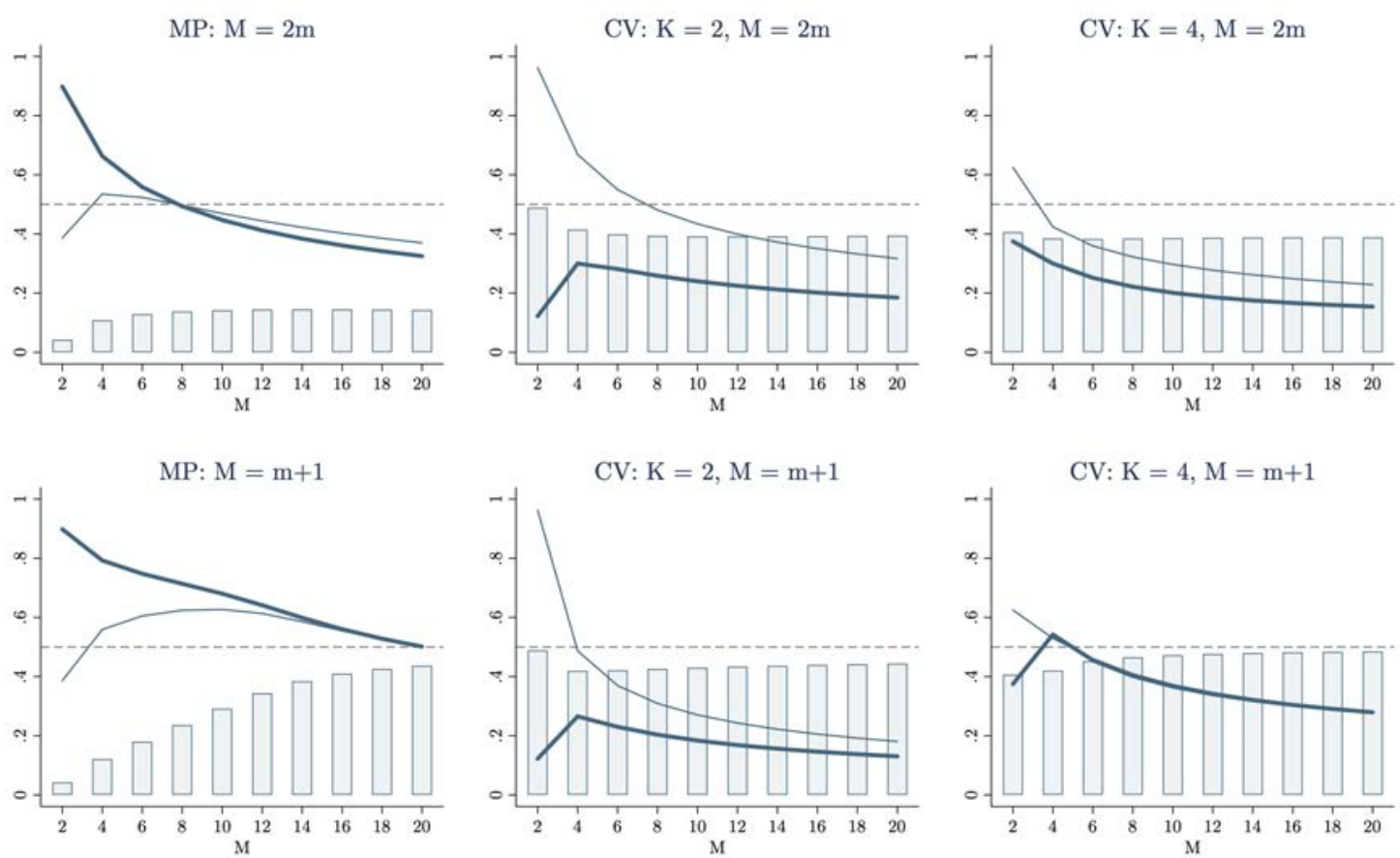

Figure 1: Expected turnout rates and share of minority seats, MP and $C V$. The thick lines correspond to $c_{\mathrm{M}}$, the thin lines to $c_{\mathrm{m}}$; the bars correspond to the expected share of minority seats. $F$ is uniform over $[0,1] ; V=4$.

\subsection{Equilibria for the experimental parametrizations}

Figure 1 shows the equilibrium turnout rates in the two parties, and the expected fraction of seats won by the minority under the two voting systems for different relative sizes of the two parties, in the upper and lower panels, different values of $M$, on the horizontal axis, and $K=2$ or 4 . (Recall that $K$ does not affect these outcomes under MP). ${ }^{12}$

The figure highlights two main regularities. First, CV consistently increases the relative turnout of the minority: whether the relative size of the two parties is large or small, whether the number of open seats is just enough for CV to differentiate itself from MP ( $K=2$, in the central panels), or is higher $(K=4$ in the panels on the right), the ratio $c_{\mathrm{m}} / c_{\mathrm{M}}$ is higher under $\mathrm{CV}$ than under MP. This remains true whether the electorate is small or large, unless the difference in size of the two parties becomes negligible (for $M=m+1$ and large $M$ ), and turnout equalizes for the two parties under both MP and CV. Second, the

\footnotetext{
${ }^{12}$ We found a unique equilibrium in all cases. Recall that with $F$ uniform, $c_{p}$ corresponds to the expected turnout rate in party $p$. We discuss in the appendix the surprising lack of a consistent underdog effect $\left(c_{\mathrm{m}}>c_{\mathrm{M}}\right)$ in the MP model. For both MP and $\mathrm{CV}$, raising $K$ to 6 does not change the qualitative results.
} 
expected fraction of seats won by the minority is consistently higher under CV. The effect is most striking when the minority is relatively small $(M=2 m)$, and its expected share of seats never rises above 14\% under MP, less than half its share of the electorate, as opposed to being consistently close to $40 \%$ under CV.

The difference in outcomes between MP and CV is driven by the difference in the number of candidates. In all cases, the minority party sets $g<K$ under CV; when $G=K$, the minority's cumulation of votes results in a higher probability of affecting the outcome, incentivizing turnout; when $G<K$, the difference in turnout probabilities is reduced, but the share of minority victories is boosted by the seats left uncontested by the majority. In the figure, when $K=2$, $G=K=2$, but $g=1$ for all $M$ and $m$; when $K=4, G=3$ always; $g=2$ if $m=M / 2 ; g=3$ otherwise. Thus in the lower right panel, $g=G=3$, and the two parties' turnout probabilities converge, but the uncontested seat keeps the share of expected minority victories higher than under MP.

We can compare the results to minority victories in the absence of voting costs, and thus of turnout effects. Under MP, as we know, the minority never wins any seat, as opposed to the less than proportional but positive share predicted with voting costs. Under CV and costless voting, the expected share of minority victories is $1 / 2$ if $m=M-1>1$, and either $1 / 3$ (if $K=2$ ) or $1 / 4$ (if $K=4)$ if $m=M / 2$. Accounting for turnout thus softens the impact of relative party size, reducing expected minority victories for $m=M-1$, but increasing them for $m=M / 2$. Under CV, the minority always achieves substantive representation but is expected to maintain its minority status in the allocation of seats.

\section{The Experiment}

The experiment reproduces exactly the theoretical model. Our main focus is the comparison between turnout, for both parties, and the fraction of minority victories under the two voting rules, MP and $\mathrm{CV}$. To evaluate the robustness of the results and to test the power of the theoretical framework we implemented four different parametrizations: while we kept $M=4$ throughout the experiment, we varied $m$ between 2 and 3 ; for each $m$, we set $K=2$ and $K=4$. In

all treatments, voting costs were drawn independently across participants from a uniform distribution with support $[0,100]$, and $V$, the value of controlling all positions, was set at 400 . 


\begin{tabular}{lccc|ccc|cc}
\hline \hline & & & & & & & Exp. Min. & Exp. Min. \\
Seats & Share \\
\hline \hline 4,2 & 2 & MP & 2,2 & 0.54 & 0.66 & 0.81 & 0.22 & 0.11 \\
4,2 & 2 & CV & 2,1 & 0.67 & 0.30 & 2.23 & 0.84 & 0.42 \\
& & & & & & & & \\
4,2 & 4 & MP & 4,4 & 0.54 & 0.66 & 0.81 & 0.44 & 0.11 \\
4,2 & 4 & CV & 3,2 & 0.42 & 0.30 & 1.41 & 1.52 & 0.38 \\
& & & & & & & & \\
4,3 & 2 & MP & 2,2 & 0.56 & 0.79 & 0.71 & 0.24 & 0.12 \\
4,3 & 2 & CV & 2,1 & 0.49 & 0.27 & 1.84 & 0.84 & 0.42 \\
& & & & & & & & \\
4,3 & 4 & MP & 4,4 & 0.56 & 0.79 & 0.71 & 0.48 & 0.12 \\
4,3 & 4 & CV & 3,3 & 0.53 & 0.54 & 0.98 & 1.68 & 0.42 \\
\hline \hline
\end{tabular}

Table 1: Experimental Design and Predictions. $F$ uniform over $[0,100] ; V=$ 400 .

The number of candidates fielded by each party under CV was set at the theoretically optimal value for each parametrization and we constrained voters who turned out to spread their votes equally over their party candidates. Participants acted as eligible voters: at each round, each drew an independent voting cost and decided whether or not to vote. The design thus mimics the numerical simulations, with $M=4$. We reproduce it in Table 1, together with the theoretical predictions.

The table dictates the hypotheses to test. The first set concerns the propensities to turnout, $\left\{c_{\mathrm{m}}, c_{\mathrm{M}}\right\}$. First, in all parametrizations, the relative minority/majority turnout $\left(c_{\mathrm{m}} / c_{\mathrm{M}}\right)$ is strictly higher under CV than under MP (H1). Second, under MP the turnout rate is higher for the majority; under CV it is higher for the minority in three of the four parametrizations, and barely lower in the fourth (H2). The second set of hypotheses concerns expected minority victories. First, in all parametrizations the expected share of seats won by the minority is higher under CV than under MP (H3). Second, as a check of the theoretical model, the share varies with the voting rule but for each rule is very close to constant across parametrizations (H4).

We conducted the experiment between August and October 2020, with participants recruited using the Columbia Experimental Laboratory for the Social Sciences (CELSS)' Orsee website ${ }^{13}$. Most subjects were undergraduate students at Columbia University or Barnard College. All sessions were online due to the COVID-19 pandemic: participants received instructions and communicated

\footnotetext{
${ }^{13}$ Greiner (2015).
} 
with experimenters using the Zoom videoconferencing software, and accessed the experiment interface on their personal computer's web browser. The experiment was programmed in z-Tree (Fischbacher, 2007) and run virtually using z-Tree unleashed (Duch et al., 2020). Each experimental session lasted about 90 minutes with average earnings of $\$ 23$. With the exception of a more visual style for the instructions, the experiment developed very similarly to in-person experiments in the lab. ${ }^{14}$

During each session, party sizes were kept fixed, and participants played 15 consecutive rounds each of four treatments, CV and MP for each of $K=2$ and $K=4$, in an order that changed across sessions. Party affiliations were kept constant within each treatment to facilitate learning but were assigned randomly across treatments. In each round, two groups were formed randomly, each composed of $m$ minority and $M$ majority members. At the end of the round, an outcome screen reported the party affiliations of the $K$ winning candidates and the number of members of each party who had voted. Each participant's final earnings corresponded to the sum of their earnings from one randomly drawn round from each treatment (in addition to the $\$ 5$ show-up fee). For given $m$, either 2 or 3 , we ran two experimental sessions for each of four orders of treatments. Thus eight sessions were conducted with $m=2(12$ subjects per session), and eight with $m=3$ (14 subjects per session), for a total of 208 experimental subjects.

\section{Experimental Results}

Figure 2 reports the turnout rates for minority and majority voters in the different treatments, in the upper panels, and the two parties' relative rate in the lower panel.

For all experimental values of $K$ and $m$, minority turnout is higher under CV than under MP. The effect is particularly strong for $m=2$, but remains consistently positive, if more muted, with $m=3$ as well. The difference remains positive even when theory predicts instead a decline in turnout. Interestingly, with the single exception of $m=3$ and $K=2$, the predicted decline in turnout for the majority under $\mathrm{CV}$ is not observed in the lab: majority turnout remains mostly constant.

The lower panel shows the final effect on relative turnout frequencies: in all

\footnotetext{
${ }^{14}$ The online appendix contains a reproduction of the instructions.
} 

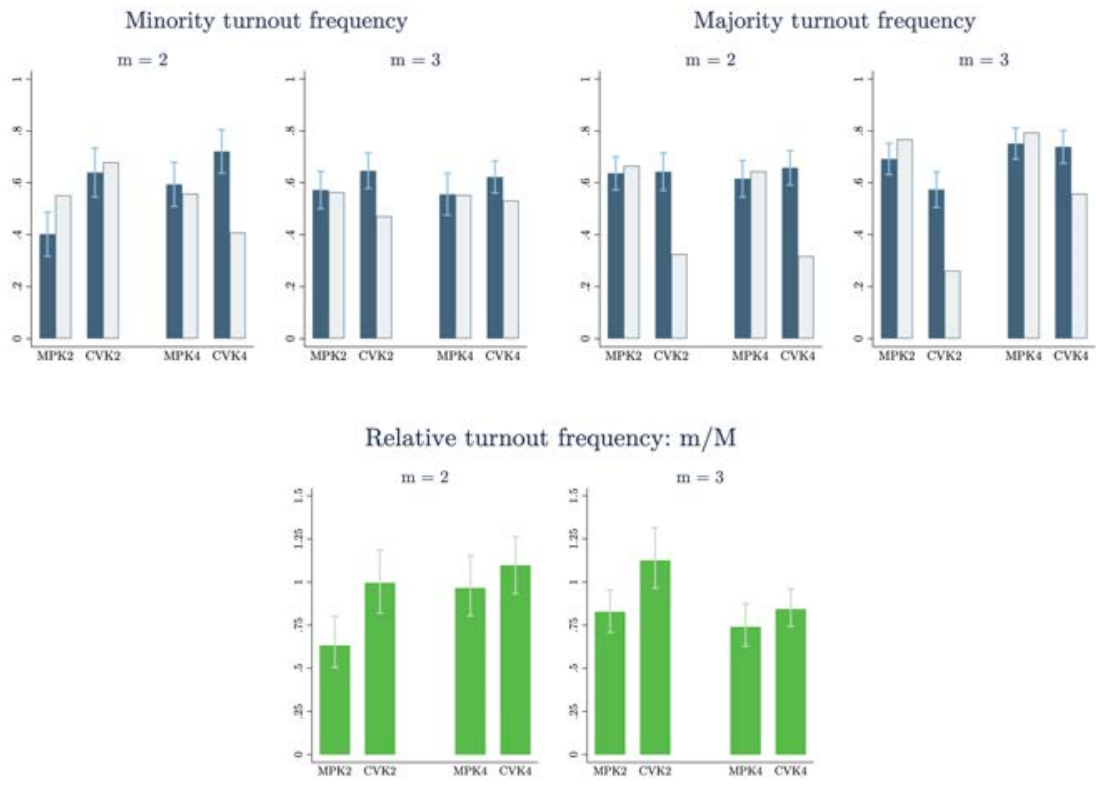

Figure 2: Turnout frequencies. Upper panels: the 95\% CI's reflect standard errors clustered at the individual level. Lower panel: the $95 \%$ CI's are calculated from 10,000 Monte Carlo simulations that allow from correlation in turnout decisions at the individual level. The grey bars in the upper panel correspond to the theory.

cases, the minority's relative turnout rate increases under CV. The theory also predicts that the minority's turnout rate should be lower than the majority's in all MP treatments, higher in three of the four CV treatments, and barely lower in the fourth. The comparative prediction is again satisfied in all cases.

We analyze the data more precisely in regressions we report in the appendix, where the effects discussed here are all strongly confirmed. The regressions control for the realized voting cost, the order of treatment, and the round number; we find no effect for the order of treatment, and a significant but quantitatively small decline in turnout, comparable for both parties as experience increases.

Summarizing then, CV increases the minority's turnout, both in absolute terms and relative to the majority, supporting both hypotheses H1 and H2. The most noticeable deviation from the theory is the majority's persistently high turnout under CV. ${ }^{15}$

\footnotetext{
${ }^{15} \mathrm{As}$ a result, total turnout, predicted to fall under $\mathrm{CV}$, remains in fact constant in the lab.
} 

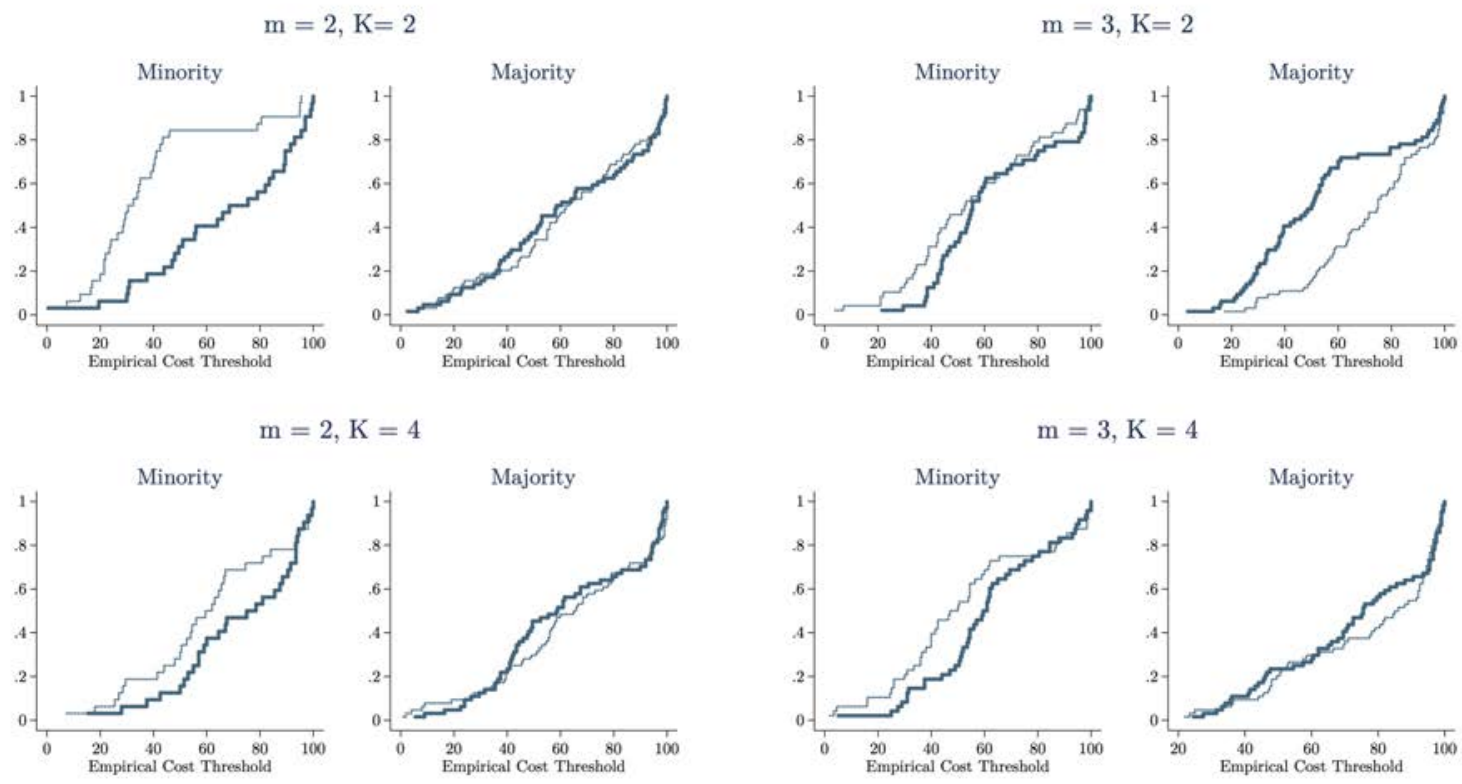

Figure 3: CDF's of Cost Cutpoints. The dotted lines correspond to MP; the solid lines to $\mathrm{CV}$.

Figure 2 invites a natural question: CV affects positively the minority's propensity to vote, but does the aggregate effect mirror a widespread change in behavior, or the changed attitude of a few outliers? Figure 3 addresses the question by reporting the CDF's of the individual cutpoints estimated from our data.

The minority's higher propensity to vote under CV operates throughout the distribution of individual cutpoints. Especially with $m=2$, when the minority is half the majority, the move to CV causes an unambiguous shift rightward of the whole distribution: the minority cutpoints distribution under CV FOSD's the distribution under MP. The effect is particularly strong when $K=2$, and under CV the minority cumulates all votes on a single candidate $(g=1)$ : CV makes the prospect of winning one seat realistic and encourages participation. When $m=3$ and the difference in size between the two parties is smaller, the minority still shifts homogeneously towards higher turnout but the move is less pronounced.

As for the majority, with $m=2$, majority members barely modify their propensity to vote. With $m=3$, the conclusion is similar when $K=4$; when $K=2$, however, under CV the majority is certain of one victory and doubts their ability to control the second seat. The result, as predicted, is a consistent We discuss the data on total turnout in the appendix. 


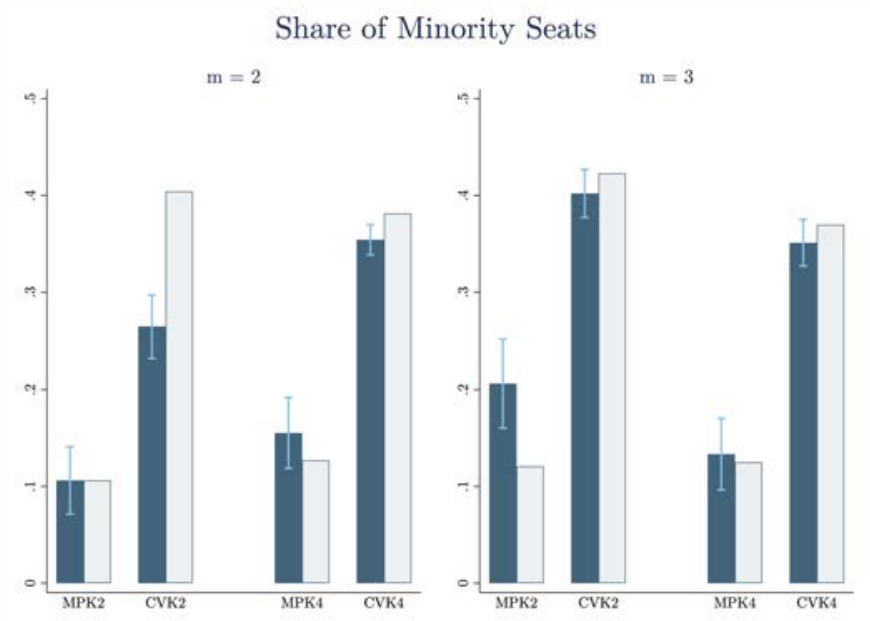

Figure 4: Share of seats won by the minority. Blue columns correspond to the data, grey to the theory. The $95 \%$ CI's are calculated from standard errors clustered at the level of the voting group.

decline in voting throughout the majority's cutpoint distribution: the distribution under MP FOSD's the distribution under CV. As remarked earlier, it is the only case in which the predicted decline in majority's turnout is seen in the data.

Figure 3 also shows the heterogeneity in behavior we see in the lab. Under both voting rules and for all parametrizations, the theoretical CDF's have a single step at the equilibrium cutpoint; in line with previous results from similar experiments ${ }^{16}$, this is not what we see in the data.

Did CV help the minority secure more seats? Figure 4 shows that the answer is positive.

For every parametrization, CV increases the fraction of minority victories, and does so very significantly, both quantitatively and statistically. As confirmed by regressions reported in the appendix, the data strongly support hypothesis H3. ${ }^{17}$ As for hypothesis H4, supported too is the prediction that the differences in minority victories should be larger across voting rules, for given parametrization, than across parametrizations, for given voting rule. The point prediction of constant share of minority victories across parametrizations, for given voting rule, fares slightly less well, with the largest exception the fewer

${ }^{16}$ For example, Levine and Palfrey (2007).

${ }^{17}$ As predicted, however, the share of minority victories remains under $50 \%$ in all cases. 
than expected successes of the minority under CV when $K=2$ and $m=2$, reflecting the unexpected high turnout of the majority in this treatment. Even in this case, however, the share of minority seats is more than double what it is under MP.

\section{Conclusions}

As we write, debates over voting rights rage in Congress, in state legislatures, in the courts, in the media. Initiatives aimed at limiting access to the polls and the prospect of partisan redistricting following the 2020 census increase fears of disenfranchisement. Encouraging minority turnout and making the political process more robust to gerrymandering are high priorities. Voting rules like CV have the potential to help both. In the lab, such potential is fulfilled.

\section{References}

Arzumanyan, M. and M Polborn, 2017, "Costly voting with multiple candidates under plurality rule", Games and Economic Behavior, 106, 38-50

Bowler, S., D. Brockington, and T. Donovan, 2001, "Election Systems and Voter Turnout: Experiments in the United States", Journal of Politics, 63, 902-915.

Bowler, S., T. Donovan, and D. Farrell, 1999, "Party Strategy and Voter Organization under Cumulative Voting in Victorian England", Political Studies, XLVII, 906-917.

Bowler, S., T. Donovan, and D. Brockington, 2003, Electoral Reform and Minority Representation: Local Experiments with Alternative Elections, Ohio State University Press.

Brockington, D., T. Donovan, S. Bowler, and R. Brischetto, 1998, "Minority Representation under Cumulative and Limited Voting", Journal of Politics, 60, 1108-25.

Cooper, D., and A. Zillante, 2012, "A Comparison of Cumulative Voting and Generalized Plurality Voting", Public Choice 150, 363-83.

Dodgson, Charles, 1884, The Principles of Parliamentary Representation, London, Harrison and Sons.

Duch, M. L., Grossmann, M. R. P. and Lauer, T., 2020, "z-Tree unleashed: A novel client-integrating architecture for conducting $\mathrm{z}$-Tree experiments over 
the Internet", Journal of Behavioral and Experimental Finance, 28.

Engstrom, R., 2010, "Cumulative and Limited Voting: Minority Electoral Opportunities and More", Saint Louis University Public Law Review 30, 97-138.

Fischbacher, U., 2007, "z-Tree: Zurich toolbox for ready-made economic experiments", Experimental Economics 10, 171-178.

Gerber, E.., R. Morton, and T. Rietz, 1998, "Minority Representation in Multimember Districts", American Political Science Review 92, 127-44.

Goldburg, C., 1994, "The Accuracy of Game Theory Predictions for Political Behavior: Cumulative Voting in Illinois Revisited", Journal of Politics, 56, 885900

Greiner, B., 2015, "Subject Pool Recruitment Procedures: Organizing Experiments with ORSEE", Journal of the Economic Science Association, 1, 114125.

Grofman, B., L. Handley, and R. Niemi, 1992, Minority Representation and the Quest for Voting Equality, Cambridge: Cambridge University Press.

Guinier, Lani, 1994, The Tyranny of the Majority, Free Press: New York, NY.

Herrera, H., M. Morelli and T. Palfrey, 2014, "Turnout and Power Sharing", Economic Journal, 124, F131-F162.

Ledyard, J., 1984, "The pure theory of large two-candidate elections", Public Choice, 44, 7-41.

Levine, D., \& Palfrey, T., 2007, "The Paradox of Voter Participation? A Laboratory Study", American Political Science Review, 101, 143-158.

Levine, D. and A. Mattozzi, 2020, "Voter Turnout with Peer Punishment", American Economic Review, 110, 3298-3314.

Obama, B., 2020, A Promised Land, Random House: New York, NY.

Palfrey, T. and H. Rosenthal, 1983, "A Strategic Calculus of Voting", Public Choice, 41, 7-53.

Pildes, R. and K. Donoghue, 1995, "Cumulative Voting in the United States", University of Chicago Legal Forum: Vol. 1995, Article 10.

Riker, W. and P. Ordeshook, 1968, "A Theory of the Calculus of Voting", American Political Science Review, 62, 25-42.

Sawyer J. and D. MacRae, 1962, "Game Theory and Cumulative Voting in Illinois: 1902-1954”, American Political Science Review, 56, 936-946. 


\title{
Minority Turnout and Representation under Cumulative Voting.
}

An experiment. Appendix

\author{
Alessandra Casella Jeffrey Da-Ren Guo Michelle Jiang
}

April 2, 2021

\section{Appendix A}

\subsection{CV when voting is costless}

Proposition 1. In the absence of voting costs, for all $m, M>m$, and $K$, in all equilibria of the voting game:

$$
\begin{aligned}
& z=0 \quad \text { if } m<M / K \\
& z \in\left(\frac{K m-M}{M+m}, \frac{K m+m}{M+m}\right) \quad \text { if } m>M / K \text { and } \frac{K m-M}{M+m} \notin \mathbb{Z}_{+} \\
& z=\left\{\begin{array}{ll}
\frac{K m-M}{M+m} & \text { with prob } m /(M+m) \\
\frac{K m+m}{M+m} & \text { with prob } M /(M+m)
\end{array} \text { if } m \geq M / K \text { and } \frac{K m-M}{M+m} \in \mathbb{Z}_{+}\right.
\end{aligned}
$$

Because $(K m+m) /(M+m)-(K m-M) /(M+m)=1$, if $\frac{K m-M}{M+m}$ is not an integer, there exists a unique integer value of $z$ in the relevant interval; if $\frac{K m-M}{M+m}$ is an integer, then $\frac{K m+m}{M+m}$ is one as well.

Proof. As described in the text, the result follows because the coincidence of goals between party leaders and members allows us to simplify the game to a two-player game, and the linearity of $u(k)$ renders the game constant-sum. The proposition exploits the properties of two-player constant-sum games: in all equilibria, payoffs must equal the payoffs from the players' maximin strategies. We proceed in three stages.

(i) Suppose first that $m<M / K$. Then the M party can guarantee itself all $K$ seats by dividing its votes equally over $K$ candidates, and the m party cannot win any seat. 
(ii) Suppose then $m>M / K$. For any $x_{\mathrm{M}}$, party $m$ maximizes the probability of winning $z$ seats by dividing its votes equally over $z$ candidates, and guarantees itself $z$ seats if $m K / z>M K /(K-z+1)$, or $z<(K m+m) /(M+m)$. At the same time, party $\mathrm{M}$ maximizes the probability of winning $(K-z)$ seats by dividing its votes equally over $K-z$ candidates, and guarantees itself $K-z$ seats if $M K /(K-z)>m K /(z+1)$, or $z>$ $(K m-M) /(M+m)$. We require $z$ to be an integer.

(ii.a) Suppose first that $(K m-M) /(M+m)$ is not an integer. Since $(K m+m) /(M+m)-$ $(K m-M) /(M+m)=1$, if $(K m-M) /(M+m)$ is not an integer, then there exists a unique integer value of $z \in\left(\frac{K m-M}{M+m}, \frac{K m+m}{M+m}\right)$ and such strategies are an equilibrium: neither party has a profitable deviation. Hence an equilibrium exists. By the properties of constant-sum two-player games, it then follows that all equilibria must deliver such an outcome: many equilibria are possible, with votes divided unequally among the candidates and more than $z$ or $Z$ candidates from each party receiving positive votes, but in all equilibria the $\mathrm{m}$ party wins $z$ seats, and the $\mathrm{M}$ party $Z=K-z$ seats. $^{1}$

(ii.b and iii) Finally, suppose that either $m>M / K$ and $(K m-M) /(M+m)$ is an integer, or $m=M / K$ (and thus $(K m-M) /(M+m)=0)$. Then the $\mathrm{m}$ party can guarantee itself $(K m-M) /(M+m) \equiv \underline{z}$ seats, but can do better by spreading votes equally over $(K m-M) /(M+m)+1=(K m+m) /(M+m) \equiv \bar{z}$ candidates. Similarly, the $\mathbf{M}$ party can guarantee itself $K-\bar{z}$ seats, but can do better by spreading votes equally over $K-\bar{z}+1=K-\underline{z}$ candidates. In equilibrium then, party $\mathrm{m}(\mathrm{M})$ spreads its votes equally over $\bar{z}(K-\underline{z})$ candidates; a total of $K+1$ candidates receive votes, and all are tied with $[K /(K+1)](M+m)$ votes each. The tie-break rule selects $K$ winners randomly from the $K+1$ candidates. It then follows that

$$
\begin{aligned}
& \operatorname{Pr}(z=\bar{z})=\frac{\left(\begin{array}{l}
K-\underline{z} \\
K-\bar{z}
\end{array}\right)}{\left(\begin{array}{c}
K+1 \\
K
\end{array}\right)}=1-\frac{\bar{z}}{K+1}=\frac{M}{m+M} \\
& \operatorname{Pr}(z=\underline{z})=1-\operatorname{Pr}(z=\bar{z})=\frac{m}{m+M}
\end{aligned}
$$

\footnotetext{
${ }^{1}$ For example, suppose $K=4, M=4$, and $m=3$, which is one of our experimental parametrizations. In the absence of voting costs, in all equilibria $z=2$. One possible set of equilibrium strategies is $x_{i, \mathrm{~m}}=$ $\{2,2,0,0\}$ for all $i \in \mathrm{m}$, and $x_{i, \mathrm{M}}=\{2,2,0,0\}$ for all $i \in \mathrm{M}$. Thus two candidates in each party list receive votes and are elected: the two winning candidates in party $M$ receive 8 votes each, and the two winning candidates in party $\mathrm{m}$ receive 6 votes each. But other equilibria are possible. For example, holding voting unchanged in the minority party, three candidates from party $M$ may receive $\{7,7,2\}$ votes each. However there is no equilibrium that allows either party to win more than two seats.
} 


\subsection{Costly voting: Pivot probabilities and probabilities of winning seats}

\subsubsection{Multi-winner plurality (MP)}

We report here the binomial formulas for the pivot probabilities. Under MP, such formulas are well-known (see for example Levine and Palfrey, 2007).

$$
\begin{aligned}
\pi_{\mathrm{m}}^{T-1} & =\sum_{x=0}^{m-1}\left(\begin{array}{c}
m-1 \\
x
\end{array}\right)\left(\begin{array}{c}
M \\
x+1
\end{array}\right) F\left(c_{\mathrm{m}}\right)^{x}\left[1-F\left(c_{\mathrm{m}}\right)\right]^{m-1-x} F\left(c_{\mathrm{M}}\right)^{x+1}\left[1-F\left(c_{\mathrm{M}}\right)\right]^{M-(x+1)} \\
\pi_{\mathrm{m}}^{T} & =\sum_{x=0}^{m-1}\left(\begin{array}{c}
m-1 \\
x
\end{array}\right)\left(\begin{array}{c}
M \\
x
\end{array}\right) F\left(c_{\mathrm{m}}\right)^{x}\left[1-F\left(c_{\mathrm{m}}\right)\right]^{m-1-x} F\left(c_{\mathrm{M}}\right)^{x}\left[1-F\left(c_{\mathrm{M}}\right)\right]^{M-x}
\end{aligned}
$$

and:

$$
\begin{aligned}
\pi_{\mathrm{M}}^{T-1} & =\sum_{x=1}^{m}\left(\begin{array}{c}
m \\
x
\end{array}\right)\left(\begin{array}{c}
M-1 \\
x-1
\end{array}\right) F\left(c_{\mathrm{m}}\right)^{x}\left[1-F\left(c_{\mathrm{m}}\right)\right]^{m-x} F\left(c_{\mathrm{M}}\right)^{x-1}\left[1-F\left(c_{\mathrm{M}}\right)\right]^{M-1-(x-1)} \\
\pi_{\mathrm{M}}^{T} & =\sum_{x=0}^{m}\left(\begin{array}{c}
m \\
x
\end{array}\right)\left(\begin{array}{c}
M-1 \\
x
\end{array}\right) F\left(c_{\mathrm{m}}\right)^{x}\left[1-F\left(c_{\mathrm{m}}\right)\right]^{m-x} F\left(c_{\mathrm{M}}\right)^{x}\left[1-F\left(c_{\mathrm{M}}\right)\right]^{M-1-x}
\end{aligned}
$$

The frequency of minority victories is sensitive to the relative turnout rates of the two parties, captured by the ratio of the two thresholds, $c_{\mathrm{m}} / c_{\mathrm{M}}$. Although the study of costly voting models has identified an "underdog effect" - the tendency for the minority's turnout rate to be higher than the majority's, or $c_{m}>c_{M}$ - the existence of such an effect is sensitive to the exact specification of the model. It has been proven in a number of scenarios: when the voting cost is fixed and equal for all (Taylor and Yildirim, 2010a); when voters' direction of preferences is randomly drawn (Ledyard, 1984; Taylor and Yildirim, 2010b); when the size of the electorate is uncertain (Herrera et al., 2014; Krishna and Morgan, 2015). The specification used here differs from these models, and relative turnout under MP depends on $V$, the value of winning all seats. Because the model is widely used but this observation is missing from the literature, we make it explicit in the following remark.

Remark. For any finite $M, m$, and $F$ there exists a finite $\widehat{V}(M, m)$ such that if $V=\widehat{V}$, then $c_{\mathrm{m}}=c_{\mathrm{M}}$.

Proof. Call $\widehat{c}$ the median of $F(c)$. Straightforward manipulations of the pivot probabilities show that if $c_{\mathrm{m}}=c_{\mathrm{M}}=\widehat{c}$, and thus $F\left(c_{\mathrm{m}}\right)=1-F\left(c_{\mathrm{M}}\right)=1 / 2$, then $\left(\pi_{\mathrm{m}}^{T}+\pi_{\mathrm{m}}^{T-1}\right)=$ $\left(\pi_{\mathrm{M}}^{T}+\pi_{\mathrm{M}}^{T-1}\right)=(1 / 2)^{M+m-1}\left(\begin{array}{c}M+m \\ m\end{array}\right)$. Hence for any $M$ and $m, c_{\mathrm{m}}=c_{\mathrm{M}}=\widehat{c}$ is an equilibrium as long as $\widehat{c}=(V / 2)(1 / 2)^{M+m-1}\left(\begin{array}{c}M+m \\ m\end{array}\right)$, or $V=\widehat{c}\left(2^{(M+m)} /\left(\begin{array}{c}M+m \\ m\end{array}\right)\right)=\widehat{V}$. 
Note that our focus is not on the two parties' relative turnout per se, but on the impact on such relative turnout of the voting rule.

The derivation of the probabilities of winning different numbers of seats is straightforward. Consider the problem from the perspective of a minority voter. Begin with the probability of losing all positions, $\operatorname{Pr}\left(W_{\mathrm{m}}=0\right)$. Such probability equals the probability that either all minority candidates receive strictly fewer votes than the majority candidates, or that all candidates are tied but minority candidates lose all tie-breaks. Or, $\operatorname{Pr}\left(W_{\mathrm{m}}=0\right)=\operatorname{Pr}\left(S_{\mathrm{m}}<S_{\mathrm{M}}\right)+\operatorname{Pr}\left[\left(S_{\mathrm{m}}=S_{\mathrm{M}}\right) \cap(\mathrm{m}\right.$ loses all tie-breaks $\left.)\right]$. That is:

$$
\begin{aligned}
\operatorname{Pr}\left(W_{\mathrm{m}}\right. & =0)= \\
& =\sum_{S_{\mathrm{M}}=1}^{M}\left(\begin{array}{c}
M \\
S_{\mathrm{M}}
\end{array}\right) F\left(c_{\mathrm{M}}\right)^{S_{\mathrm{M}}}\left[1-F\left(c_{\mathrm{M}}\right)\right]^{M-S_{\mathrm{M}}} \sum_{S_{\mathrm{m}}=0}^{S_{\mathrm{M}}-1}\left(\begin{array}{c}
m \\
S_{\mathrm{m}}
\end{array}\right) F\left(c_{\mathrm{m}}\right)^{S_{\mathrm{m}}}\left[1-F\left(c_{\mathrm{m}}\right)\right]^{m-S_{\mathrm{m}}}+ \\
& +\sum_{S_{\mathrm{M}}=0}^{M}\left(\begin{array}{c}
M \\
S_{\mathrm{M}}
\end{array}\right)\left(\begin{array}{c}
m \\
S_{\mathrm{M}}
\end{array}\right) F\left(c_{\mathrm{M}}\right)^{S_{\mathrm{M}}}\left[1-F\left(c_{\mathrm{M}}\right)\right]^{M-S_{\mathrm{M}}} \times \\
& \times F\left(c_{\mathrm{m}}\right)^{S_{\mathrm{M}}}\left[1-F\left(c_{\mathrm{m}}\right)\right]^{m-S_{\mathrm{M}}}\left(1 /\left(\begin{array}{c}
2 K \\
K
\end{array}\right)\right)
\end{aligned}
$$

Similarly, the probability that $\mathrm{m}$ wins all positions, $\operatorname{Pr}\left(W_{\mathrm{m}}=K\right)$ equals the probability that either all minority candidates receive strictly more votes than the majority candidates, or that all candidates are tied but minority candidates win all tie-breaks. Or, $\operatorname{Pr}\left(W_{\mathrm{m}}=K\right)=\operatorname{Pr}\left(S_{\mathrm{m}}>S_{\mathrm{M}}\right)+\operatorname{Pr}\left[\left(S_{\mathrm{m}}=S_{\mathrm{M}}\right) \cap(\mathrm{m}\right.$ wins all tie-breaks $\left.)\right]$. That is:

$$
\begin{aligned}
\operatorname{Pr}\left(W_{\mathrm{m}}\right. & =K)= \\
& =\sum_{S_{\mathrm{M}}=0}^{m-1}\left(\begin{array}{c}
M \\
S_{\mathrm{M}}
\end{array}\right) F\left(c_{\mathrm{M}}\right)^{S_{\mathrm{M}}}\left[1-F\left(c_{\mathrm{M}}\right)\right]^{M-S_{\mathrm{M}}} \sum_{S_{\mathrm{m}}=S_{\mathrm{M}}+1}^{m}\left(\begin{array}{c}
m \\
S_{\mathrm{m}}
\end{array}\right) F\left(c_{\mathrm{m}}\right)^{S_{\mathrm{m}}}\left[1-F\left(c_{\mathrm{m}}\right)\right]^{m-S_{\mathrm{m}}}+ \\
& +\sum_{S_{\mathrm{M}}=0}^{M}\left(\begin{array}{c}
M \\
S_{\mathrm{M}}
\end{array}\right)\left(\begin{array}{c}
m \\
S_{\mathrm{M}}
\end{array}\right) F\left(c_{\mathrm{M}}\right)^{S_{\mathrm{M}}}\left[1-F\left(c_{\mathrm{M}}\right)\right]^{M-S_{\mathrm{M}}} \times \\
& \times F\left(c_{\mathrm{m}}\right)^{S_{\mathrm{M}}}\left[1-F\left(c_{\mathrm{m}}\right)\right]^{m-S_{\mathrm{M}}}\left(1 /\left(\begin{array}{c}
2 K \\
K
\end{array}\right)\right)
\end{aligned}
$$

The probabilities of other numbers of minority victories can be derived in the same fashion. The probability of electing $w$ minority candidates, with $w \in(0, K)$ equals the probability that all candidates are tied and $\mathrm{m}$ wins $w$ tie-breaks. Thus: 


$$
\begin{aligned}
\operatorname{Pr}\left(W_{\mathrm{m}}\right. & =w)= \\
& =\sum_{S_{\mathrm{M}}=0}^{M}\left(\begin{array}{c}
m \\
S_{\mathrm{M}}
\end{array}\right) F\left(c_{\mathrm{m}}\right)^{S_{\mathrm{M}}}\left[1-F\left(c_{\mathrm{m}}\right)\right]^{m-S_{\mathrm{M}}} \times \\
& \times\left(\begin{array}{c}
M \\
S_{\mathrm{M}}
\end{array}\right) F\left(c_{\mathrm{M}}\right)^{S_{\mathrm{M}}}\left[1-F\left(c_{\mathrm{M}}\right)\right]^{M-S_{\mathrm{M}}}\left(\begin{array}{c}
K \\
w
\end{array}\right)\left(\begin{array}{c}
K \\
K-w
\end{array}\right) /\left(\begin{array}{c}
2 K \\
K
\end{array}\right)
\end{aligned}
$$

For given $M, m, K, F(c)$, and $\{u(k)\}$, the equilibrium yields expected turnout rates for voters of the two parties, the probabilities of winning $0,1, . ., K$ positions for each party, and ex ante expected utility for an $\mathrm{M}$ and an $\mathrm{m}$ voter. $^{2}$

\subsubsection{Cumulative Voting (CV)}

Consider first the perspective of a majority voter. The pivot probabilities correspond to the probabilities of the three events described in the text-breaking a tie (if $(K / G) S_{\mathrm{M}-\mathrm{i}}=$ $\left.(K / g) S_{\mathrm{m}}\right)$, making a tie (if $\left.(K / G)\left(S_{\mathrm{M}-\mathrm{i}}+1\right)=(K / g) S_{\mathrm{m}}\right)$, or moving the outcome from a loss to a win on all contested positions (if $S_{\mathrm{M}-\mathrm{i}} \in\left(S_{\mathrm{m}}(G / g)-1, S_{\mathrm{m}}(G / g)\right)$ ). Note that since $S_{\mathrm{M}-i}$ and $S_{\mathrm{m}}$ are non-negative integers, the first event is only possible if either $G / g$ is an integer, or $S_{\mathrm{M}-i}=S_{\mathrm{m}}=0$; the second event is only possible if $G / g$ is an integer, and the third event is only possible if $G / g$ is not an integer.

The equations corresponding to the pivot probabilities are logically straightforward:

$$
\begin{gathered}
\tilde{\pi}_{\mathrm{M}}^{T}=I_{Q}\left[(G / g) S_{\mathrm{m}}\right] \sum_{S_{\mathrm{m}}=0}^{m}\left\{\left(\begin{array}{c}
m \\
S_{\mathrm{m}}
\end{array}\right) F\left(c_{\mathrm{m}}\right)^{S_{\mathrm{m}}}\left[1-F\left(c_{\mathrm{m}}\right)\right]^{m-S_{\mathrm{m}}}\right. \\
\left.\left(\begin{array}{c}
M-1 \\
(G / g) S_{\mathrm{m}}
\end{array}\right) F\left(c_{\mathrm{M}}\right)^{(G / g) S_{\mathrm{m}}}\left[1-F\left(c_{\mathrm{M}}\right)\right]^{M-1-(G / g) S_{\mathrm{m}}}\right\} \\
\tilde{\pi}_{\mathrm{M}}^{T-1}=I_{Q}\left[(G / g) S_{\mathrm{m}}\right] \sum_{S_{\mathrm{m}}=1}^{m}\left\{\left(\begin{array}{c}
m \\
S_{\mathrm{m}}
\end{array}\right) F\left(c_{\mathrm{m}}\right)^{S_{\mathrm{m}}}\left[1-F\left(c_{\mathrm{m}}\right)\right]^{m-S_{\mathrm{m}}}\right. \\
\left.\left(\begin{array}{c}
M-1 \\
(G / g) S_{\mathrm{m}}-1
\end{array}\right) F\left(c_{\mathrm{M}}\right)^{(G / g) S_{\mathrm{m}}-1}\left[1-F\left(c_{\mathrm{M}}\right)\right]^{M-1-\left[(G / g) S_{\mathrm{m}}-1\right]}\right\}
\end{gathered}
$$

\footnotetext{
${ }^{2}$ Note in particular that if $u(K)-E u_{T}^{M P}=E u_{T}^{M P}-u(0)$, or $E u_{T}^{M P}=[u(K)-u(0)] / 2$, the equilibrium thresholds $\left\{c_{\mathrm{m}}, c_{\mathrm{M}}\right\}$ are identical to the thresholds that solve the corresponding costly voting problem with a single winner.
} 
and

$$
\begin{gathered}
\widetilde{\pi}_{\mathrm{M}}^{W}=\left(1-I_{Q}\left[(G / g) S_{\mathrm{m}}\right]\right) \sum_{S_{\mathrm{m}}=0}^{m}\left\{\left(\begin{array}{c}
m \\
S_{\mathrm{m}}
\end{array}\right) F\left(c_{\mathrm{m}}\right)^{S_{\mathrm{m}}}\left[1-F\left(c_{\mathrm{m}}\right)\right]^{m-S_{\mathrm{m}}}\right. \\
\left.\left(\begin{array}{c}
M-1 \\
\left\lfloor(G / g) S_{\mathrm{m}}\right\rfloor
\end{array}\right) F\left(c_{\mathrm{M}}\right)^{\left\lfloor(G / g) S_{\mathrm{m}}\right\rfloor}\left[1-F\left(c_{\mathrm{M}}\right)\right]^{M-1-\left\lfloor(G / g) S_{\mathrm{m}}\right\rfloor}\right\}
\end{gathered}
$$

where $I_{Q}\left[(G / g) S_{\mathrm{m}}\right]=1$ if $(G / g) S_{\mathrm{m}}$ is an integer, and 0 otherwise, and $\lfloor x\rfloor$ is the floor function, denoting the greatest integer smaller or equal to $x .^{3}$

The problem is analogous for a minority voter. The relevant equations are:

$$
\begin{gathered}
\tilde{\pi}_{\mathrm{m}}^{T}=I_{Q}\left[(g / G) S_{\mathrm{M}}\right]\left\{\sum_{S_{\mathrm{M}}=0}^{M}\left(\begin{array}{c}
M \\
S_{\mathrm{M}}
\end{array}\right) F\left(c_{\mathrm{M}}\right)^{S_{\mathrm{M}}}\left[1-F\left(c_{\mathrm{M}}\right)\right]^{M-S_{\mathrm{M}}}\right. \\
\left.\left(\begin{array}{c}
m-1 \\
(g / G) S_{\mathrm{M}}
\end{array}\right) F\left(c_{\mathrm{m}}\right)^{(g / G) S_{\mathrm{M}}}\left[1-F\left(c_{\mathrm{m}}\right)\right]^{m-1-(g / G) S_{\mathrm{M}}}\right\} \\
\tilde{\pi}_{\mathrm{m}}^{T-1}=I_{Q}\left[(g / G) S_{\mathrm{M}}\right] \sum_{S_{\mathrm{M}}=1}^{M}\left\{\left(\begin{array}{c}
M \\
S_{\mathrm{M}}
\end{array}\right) F\left(c_{\mathrm{M}}\right)^{S_{\mathrm{M}}}\left[1-F\left(c_{\mathrm{M}}\right)\right]^{M-S_{\mathrm{M}}}\right. \\
\left.\left(\begin{array}{c}
m-1 \\
(g / G) S_{\mathrm{M}}-1
\end{array}\right) F\left(c_{\mathrm{m}}\right)^{(g / G) S_{\mathrm{M}}-1}\left[1-F\left(c_{\mathrm{m}}\right)\right]^{m-1-\left[(g / G) S_{\mathrm{M}}-1\right]}\right\} \\
\widetilde{\pi}_{\mathrm{m}}^{W}=\left(\begin{array}{c}
\left.1-I_{Q}\left[(g / G) S_{\mathrm{M}}\right]\right) \sum_{S_{\mathrm{M}}=0}^{M}\left\{\left(\begin{array}{c}
M \\
S_{\mathrm{M}}
\end{array}\right) F\left(c_{\mathrm{M}}\right)^{S_{\mathrm{M}}}\left[1-F\left(c_{\mathrm{M}}\right)\right]^{M-S_{\mathrm{M}}}\right. \\
\left.\left(\begin{array}{c}
m-1 \\
\left.(g / G) S_{\mathrm{M}}\right\rfloor
\end{array}\right) F\left(c_{\mathrm{m}}\right)^{\left\lfloor(g / G) S_{\mathrm{M}}\right\rfloor}\left[1-F\left(c_{\mathrm{m}}\right)\right]^{m-1-\left\lfloor(g / G) S_{\mathrm{M}}\right\rfloor}\right\}
\end{array}\right.
\end{gathered}
$$

The probabilities of the minority winning different numbers of position can be derived as under MP, but taking into account that the number of candidates, in each party, now may differ from the number of seats. The probability of the minority losing all seats must be 0 if $G<K$; if instead $G \geq K$, then as before it equals the probability that either all minority candidates receive strictly lower votes than the majority candidates, or that all candidates

\footnotetext{
${ }^{3}$ We are also using the convention $\left(\begin{array}{l}n \\ y\end{array}\right)=0$ if $y>n$.
} 
are tied but minority candidates lose all tie-breaks. That is:

$$
\begin{aligned}
\operatorname{Pr}\left(W_{\mathrm{m}}\right. & =0 \mid G \geq K)= \\
& =\sum_{S_{\mathrm{M}}=1}^{M}\left(\begin{array}{c}
M \\
S_{\mathrm{M}}
\end{array}\right) F\left(c_{\mathrm{M}}\right)^{S_{\mathrm{M}}}\left[1-F\left(c_{\mathrm{M}}\right)\right]^{M-S_{\mathrm{M}}} \sum_{S_{\mathrm{m}}=0}^{X\left(S_{\mathrm{M}}\right)}\left(\begin{array}{c}
m \\
S_{\mathrm{m}}
\end{array}\right) F\left(c_{\mathrm{m}}\right)^{S_{\mathrm{m}}}\left[1-F\left(c_{\mathrm{m}}\right)\right]^{m-S_{\mathrm{m}}}+ \\
& +\sum_{S_{\mathrm{M}}=0}^{M}\left(\begin{array}{c}
M \\
S_{\mathrm{M}}
\end{array}\right)\left(\begin{array}{c}
m \\
(g / G) S_{\mathrm{M}}
\end{array}\right) F\left(c_{\mathrm{M}}\right)^{S_{\mathrm{M}}}\left[1-F\left(c_{\mathrm{M}}\right)\right]^{M-S_{\mathrm{M}}} \times \\
& \times F\left(c_{\mathrm{m}}\right)^{(g / G) S_{\mathrm{M}}}\left[1-F\left(c_{\mathrm{m}}\right)\right]^{m-(g / G) S_{\mathrm{M}}} I_{Q}\left[(g / G) S_{\mathrm{M}}\right]\left(\begin{array}{c}
G \\
K
\end{array}\right) /\left(\begin{array}{c}
G+g \\
K
\end{array}\right)
\end{aligned}
$$

where:

$$
X\left(S_{\mathrm{M}}\right)= \begin{cases}(g / G) S_{\mathrm{M}}-1 & \text { if }(g / G) S_{\mathrm{M}} \text { is an integer } \\ \left\lfloor(g / G) S_{\mathrm{M}}\right\rfloor & \text { otherwise }\end{cases}
$$

The probability of electing $w$ minority candidates, with $w \in(0, g)$ is 0 if $K-G>w$; it equals the probability that all candidates are tied and $m$ wins $w$ tie-breaks if $K-G<w$, and equals the probability either that all are tied and $\mathrm{m}$ loses all tie-breaks or that all $\mathrm{m}$ candidates receive fewer votes if $K-G=w$. Thus:

$$
\begin{aligned}
& \operatorname{Pr}\left(W_{\mathrm{m}}=w \mid K-G \leq w\right)= \\
& =\sum_{S_{\mathrm{M}}=0}^{M}\left(\begin{array}{c}
m \\
(g / G) S_{\mathrm{M}}
\end{array}\right) F\left(c_{\mathrm{m}}\right)^{(g / G) S_{\mathrm{M}}}\left[1-F\left(c_{\mathrm{m}}\right)\right]^{m-(g / G) S_{\mathrm{M}}} \times \\
& \times\left(\begin{array}{c}
M \\
S_{\mathrm{M}}
\end{array}\right) F\left(c_{\mathrm{M}}\right)^{S_{\mathrm{M}}}\left[1-F\left(c_{\mathrm{M}}\right)\right]^{M-S_{\mathrm{M}}} I_{Q}\left[(g / G) S_{\mathrm{M}}\right]\left(\begin{array}{c}
g \\
w
\end{array}\right)\left(\begin{array}{c}
G \\
K-w
\end{array}\right) /\left(\begin{array}{c}
G+g \\
K
\end{array}\right)+ \\
& +I_{K-G=w} \sum_{S_{\mathrm{M}}=1}^{M}\left(\begin{array}{c}
M \\
S_{\mathrm{M}}
\end{array}\right) F\left(c_{\mathrm{M}}\right)^{S_{\mathrm{M}}}\left[1-F\left(c_{\mathrm{M}}\right)\right]^{M-S_{\mathrm{M}}} \times \\
& \left(\sum_{S_{\mathrm{m}}=0}^{X\left(S_{\mathrm{M}}\right)}\left(\begin{array}{c}
m \\
S_{\mathrm{m}}
\end{array}\right) F\left(c_{\mathrm{m}}\right)^{S_{\mathrm{m}}}\left[1-F\left(c_{\mathrm{m}}\right)\right]^{m-S_{\mathrm{m}}}\right)
\end{aligned}
$$

where $I_{Q}\left[(g / G) S_{\mathrm{M}}\right]$ and $X\left(S_{\mathrm{M}}\right)$ are defined as above, and $I_{K-G=w}$ is an indicator function taking value 1 if $K-G=w$ and 0 otherwise.

Finally, the probability of electing $g$ minority candidates equals 1 if $K-G \geq g$, it equals the probability that either all minority candidates receive more votes or that all candidates 
are tied and the $g$ minority candidates win all tie-breaks. That is:

$$
\begin{aligned}
\operatorname{Pr}\left(W_{\mathrm{m}}\right. & =g \mid K-G<g)= \\
& =\sum_{S_{\mathrm{M}}=0}^{M}\left(\begin{array}{c}
m \\
(g / G) S_{\mathrm{M}}
\end{array}\right) F\left(c_{\mathrm{m}}\right)^{(g / G) S_{\mathrm{M}}}\left[1-F\left(c_{\mathrm{m}}\right)\right]^{m-(g / G) S_{\mathrm{M}}} \times \\
& \times\left(\begin{array}{c}
M \\
S_{\mathrm{M}}
\end{array}\right) F\left(c_{\mathrm{M}}\right)^{S_{\mathrm{M}}}\left[1-F\left(c_{\mathrm{M}}\right)\right]^{M-S_{\mathrm{M}}} I_{Q}\left[(g / G) S_{\mathrm{M}}\right]\left(\begin{array}{c}
G \\
K-g
\end{array}\right) /\left(\begin{array}{c}
G+g \\
K
\end{array}\right)+ \\
& \sum_{S_{\mathrm{m}}=1}^{m}\left(\begin{array}{c}
m \\
S_{\mathrm{m}}
\end{array}\right) F\left(c_{\mathrm{m}}\right)^{S_{\mathrm{m}}}\left[1-F\left(c_{\mathrm{m}}\right)\right]^{m-S_{\mathrm{m}}} \times \\
& \left(\sum_{S_{\mathrm{M}}=0}^{Y\left(S_{\mathrm{m}}\right)}\left(\begin{array}{c}
M \\
S_{\mathrm{M}}
\end{array}\right) F\left(c_{\mathrm{M}}\right)^{S_{\mathrm{M}}}\left[1-F\left(c_{\mathrm{M}}\right)\right]^{M-S_{\mathrm{M}}}\right)
\end{aligned}
$$

where:

$$
Y\left(S_{\mathrm{m}}\right)= \begin{cases}(G / g) S_{\mathrm{m}}-1 & \text { if }(G / g) S_{\mathrm{m}} \text { is an integer } \\ \left\lfloor(G / g) S_{\mathrm{m}}\right\rfloor & \text { otherwise }\end{cases}
$$

\subsection{Experimental Results}

\subsubsection{Turnout regressions and total turnout}

In Tables A1, A2, and A3, we regress subjects' turnout decisions on each subject's voting cost realization and on a series of dummy variables, reflecting $K, m$, the voting system, and all cross effects among the three variables, controlling for the round number, and the order of treatments in the session. ${ }^{4}$ The excluded case is $m=2, K=2$, MP, with treatment order 1. Standard errors, clustered at the individual level to account for multiple observations from each individual, are reported in parentheses under each parameter, above p-values, reported in brackets. We report results from both a linear probability and a probit model. The results are fully consistent across the two models.

Table A1 studies data from the minority. Under MP, the increase in the minority's relative size from $m=2$ to $m=3$ increases turnout, and so does the increase in the number of seats from $K=2$ to $K=4$, although the two effects are muted when they occur together. The most interesting result for us is the strongly positive effect of CV, especially but not only when $m$ is small and $K$ is small. The order of treatments has no detectable effect, while experience (or fatigue) at later experimental rounds causes a significant but quantitatively small decline in turnout.

\footnotetext{
${ }^{4}$ We ran four different orders: 1: $\{$ MPK2, CVK2, CVK4, MPK4 $\}, 2:\{\mathrm{CVK} 2, \mathrm{MPK} 2, \mathrm{MPK} 4, \mathrm{CVK} 4\}$, 3: $\{$ MPK4, CVK4, CVK2, MPK2\}, and 4: \{CVK4, MPK4, MPK2, CVK2\}.
} 
Table A1: Frequency of Turnout - Minority

\begin{tabular}{|c|c|c|}
\hline & Linear Probability Model & Probit Model \\
\hline $\mathrm{K}=4$ & $\begin{array}{c}0.184 \\
(0.052) \\
{[0.000]}\end{array}$ & $\begin{array}{c}0.601 \\
(0.172) \\
{[0.000]}\end{array}$ \\
\hline $\mathrm{m}=3$ & $\begin{array}{c}0.171 \\
(0.052) \\
{[0.001]}\end{array}$ & $\begin{array}{c}0.559 \\
(0.176) \\
{[0.002]}\end{array}$ \\
\hline $\mathrm{CV}$ & $\begin{array}{c}0.236 \\
(0.061) \\
{[0.000]}\end{array}$ & $\begin{array}{c}0.770 \\
(0.205) \\
{[0.000]}\end{array}$ \\
\hline$(\mathrm{K}=4) \times(m=3)$ & $\begin{array}{l}-0.199 \\
(0.069) \\
{[0.004]}\end{array}$ & $\begin{array}{l}-0.641 \\
(0.228) \\
{[0.005]}\end{array}$ \\
\hline$(\mathrm{K}=4) \times C V$ & $\begin{array}{l}-0.087 \\
(0.082) \\
{[0.291]}\end{array}$ & $\begin{array}{l}-0.249 \\
(0.281) \\
{[0.375]}\end{array}$ \\
\hline$(\mathrm{m}=3) \times C V$ & $\begin{array}{l}-0.149 \\
(0.078) \\
{[0.058]}\end{array}$ & $\begin{array}{l}-0.457 \\
(0.261) \\
{[0.080]}\end{array}$ \\
\hline$(\mathrm{K}=4) \times(m=3) \times C V$ & $\begin{array}{c}0.065 \\
(0.104) \\
{[0.537]}\end{array}$ & $\begin{array}{c}0.159 \\
(0.353) \\
{[0.652]}\end{array}$ \\
\hline Treatment order $=2$ & $\begin{array}{l}-0.024 \\
(0.044) \\
{[0.579]}\end{array}$ & $\begin{array}{l}-0.095 \\
(0.147) \\
{[0.520]}\end{array}$ \\
\hline Treatment order $=3$ & $\begin{array}{c}0.044 \\
(0.043) \\
{[0.304]}\end{array}$ & $\begin{array}{c}0.144 \\
(0.147) \\
{[0.328]}\end{array}$ \\
\hline Treatment order $=4$ & $\begin{array}{c}0.026 \\
(0.046) \\
{[0.574]}\end{array}$ & $\begin{array}{c}0.083 \\
(0.154) \\
{[0.587]}\end{array}$ \\
\hline Round & $\begin{array}{l}-0.007 \\
(0.002) \\
{[0.000]}\end{array}$ & $\begin{array}{l}-0.024 \\
(0.006) \\
{[0.000]}\end{array}$ \\
\hline Voting Cost & $\begin{array}{l}-0.008 \\
(0.000) \\
{[0.000]}\end{array}$ & $\begin{array}{l}-0.026 \\
(0.002) \\
{[0.000]}\end{array}$ \\
\hline Constant & $\begin{array}{c}0.862 \\
(0.049) \\
{[0.000]}\end{array}$ & $\begin{array}{c}1.142 \\
(0.167) \\
{[0.000]}\end{array}$ \\
\hline $\begin{array}{l}\text { Observations } \\
\mathrm{R}^{2}\end{array}$ & $\begin{array}{l}4800 \\
0.276\end{array}$ & 4800 \\
\hline
\end{tabular}


Table A2: Frequency of Turnout - Majority

\begin{tabular}{|c|c|c|}
\hline & Linear Probability Model & Probit Model \\
\hline $\mathrm{K}=4$ & $\begin{array}{l}-0.002 \\
(0.033) \\
{[0.949]}\end{array}$ & $\begin{array}{l}-0.004 \\
(0.110) \\
{[0.972]}\end{array}$ \\
\hline $\mathrm{m}=3$ & $\begin{array}{c}0.083 \\
(0.044) \\
{[0.064]}\end{array}$ & $\begin{array}{c}0.303 \\
(0.153) \\
{[0.048]}\end{array}$ \\
\hline $\mathrm{CV}$ & $\begin{array}{c}0.008 \\
(0.035) \\
{[0.810]}\end{array}$ & $\begin{array}{c}0.030 \\
(0.120) \\
{[0.805]}\end{array}$ \\
\hline$(\mathrm{K}=4) \times(m=3)$ & $\begin{array}{c}0.048 \\
(0.048) \\
{[0.318]}\end{array}$ & $\begin{array}{c}0.171 \\
(0.172) \\
{[0.320]}\end{array}$ \\
\hline$(\mathrm{K}=4) \times C V$ & $\begin{array}{c}0.020 \\
(0.045) \\
{[0.657]}\end{array}$ & $\begin{array}{c}0.070 \\
(0.155) \\
{[0.651]}\end{array}$ \\
\hline$(\mathrm{m}=3) \times C V$ & $\begin{array}{l}-0.137 \\
(0.052) \\
{[0.009]}\end{array}$ & $\begin{array}{l}-0.470 \\
(0.176) \\
{[0.008]}\end{array}$ \\
\hline$(\mathrm{K}=4) \times(m=3) \times C V$ & $\begin{array}{c}0.082 \\
(0.066) \\
{[0.218]}\end{array}$ & $\begin{array}{c}0.284 \\
(0.232) \\
{[0.220]}\end{array}$ \\
\hline Treatment order $=2$ & $\begin{array}{c}0.033 \\
(0.045) \\
{[0.456]}\end{array}$ & $\begin{array}{c}0.128 \\
(0.158) \\
{[0.418]}\end{array}$ \\
\hline Treatment order $=3$ & $\begin{array}{l}0.025 \\
(0.045) \\
{[0.581]}\end{array}$ & $\begin{array}{c}0.090 \\
(0.158) \\
{[0.567]}\end{array}$ \\
\hline Treatment order $=4$ & $\begin{array}{c}0.011 \\
(0.049) \\
{[0.824]}\end{array}$ & $\begin{array}{c}0.046 \\
(0.170) \\
{[0.787]}\end{array}$ \\
\hline Round & $\begin{array}{l}-0.005 \\
(0.001) \\
{[0.000]}\end{array}$ & $\begin{array}{l}-0.019 \\
(0.004) \\
{[0.000]}\end{array}$ \\
\hline Voting Cost & $\begin{array}{l}-0.008 \\
(0.000) \\
{[0.000]}\end{array}$ & $\begin{array}{l}-0.026 \\
(0.001) \\
{[0.000]}\end{array}$ \\
\hline Constant & $\begin{array}{c}1.039 \\
(0.045) \\
{[0.000]}\end{array}$ & $\begin{array}{c}1.793 \\
(0.171) \\
{[0.000]}\end{array}$ \\
\hline $\begin{array}{l}\text { Observations } \\
R^{2}\end{array}$ & $\begin{array}{l}7680 \\
0.246\end{array}$ & 7680 \\
\hline
\end{tabular}


Table A2 shows the results for the majority. Under MP, the regression finds a small and only marginally significant increase in turnout with $m=3$. Under $\mathrm{CV}$, there is a decline in turnout in the $m=3, K=2$ case, but the most noticeable result is the lack of the predicted decline in the other parametrizations. Overall, majority turnout remains relatively constant, regardless of the voting system or the values of $K$ and $m$. For the majority too we find no effect of treatment order and a small significant decline in turnout at later rounds.

Although our interest is primarily in the effect of the voting rule on the parties' relative turnout rates, a natural policy concern is the impact of $\mathrm{CV}$ on turnout as a whole. The results described in the text, separately for minority and majority, can be aggregated to yield the answer, but it is convenient to report directly our findings on total turnout. Figure A1 reports barcharts of the experimental subjects' turnout frequency under the different parametrizations and the two voting rules, with no distinction based on party affiliation.
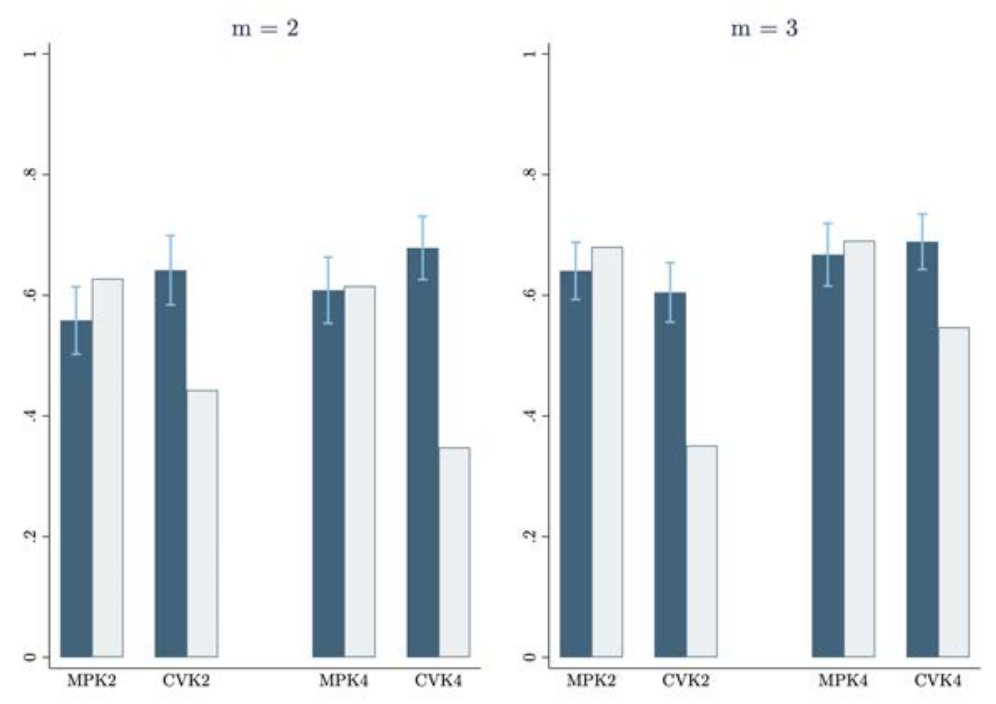

Figure A1: Turnout rate (all voters). The dark columns are the data, the light grey columns the theoretical predictions. 95\% CI's are calculated from standard errors clustered at the individual level.

The main message is that turnout is little affected by the voting rule and the changes in parametrization. The regression results reported in Table A3 lend precision to the statement. The table is formatted as Tables A1 and A2, with standard errors (in parentheses) and pvalues (in brackets) reported under each parameter; as in the previous tables, the excluded case is $m=2, K=2$, MP, with treatment order 1 . Given MP, the increase in $m$ from 2 to 3 increases the electorate's propensity to turnout, and given $m=2$, switching from MP to $\mathrm{CV}$ again increases turnout. The positive effect of CV, however, is reduced under $m=3$. The final lesson remains that the net effects are small. 
Table A3: Frequency of Turnout - All Voters

\begin{tabular}{|c|c|c|}
\hline & Linear Probability Model & Probit Model \\
\hline $\mathrm{K}=4$ & $\begin{array}{c}0.061 \\
(0.028) \\
{[0.031]}\end{array}$ & $\begin{array}{c}0.196 \\
(0.090) \\
{[0.029]}\end{array}$ \\
\hline $\mathrm{m}=3$ & $\begin{array}{c}0.099 \\
(0.037) \\
{[0.007]}\end{array}$ & $\begin{array}{c}0.329 \\
(0.120) \\
{[0.006]}\end{array}$ \\
\hline $\mathrm{CV}$ & $\begin{array}{c}0.084 \\
(0.028) \\
{[0.003]}\end{array}$ & $\begin{array}{c}0.273 \\
(0.093) \\
{[0.003]}\end{array}$ \\
\hline$(\mathrm{K}=4) \times(m=3)$ & $\begin{array}{l}-0.041 \\
(0.040) \\
{[0.305]}\end{array}$ & $\begin{array}{l}-0.132 \\
(0.133) \\
{[0.319]}\end{array}$ \\
\hline$(\mathrm{K}=4) \times C V$ & $\begin{array}{l}-0.016 \\
(0.037) \\
{[0.657]}\end{array}$ & $\begin{array}{l}-0.040 \\
(0.123) \\
{[0.743]}\end{array}$ \\
\hline$(\mathrm{m}=3) \times C V$ & $\begin{array}{l}-0.121 \\
(0.037) \\
{[0.001]}\end{array}$ & $\begin{array}{l}-0.385 \\
(0.124) \\
{[0.002]}\end{array}$ \\
\hline$(\mathrm{K}=4) \times(m=3) \times C V$ & $\begin{array}{c}0.065 \\
(0.050) \\
{[0.190]}\end{array}$ & $\begin{array}{c}0.213 \\
(0.168) \\
{[0.205]}\end{array}$ \\
\hline Treatment order $=2$ & $\begin{array}{c}0.011 \\
(0.038) \\
{[0.767]}\end{array}$ & $\begin{array}{c}0.038 \\
(0.127) \\
{[0.767]}\end{array}$ \\
\hline Treatment order $=3$ & $\begin{array}{c}0.032 \\
(0.039) \\
{[0.406]}\end{array}$ & $\begin{array}{c}0.106 \\
(0.131) \\
{[0.418]}\end{array}$ \\
\hline Treatment order $=4$ & $\begin{array}{c}0.017 \\
(0.041) \\
{[0.682]}\end{array}$ & $\begin{array}{c}0.060 \\
(0.136) \\
{[0.661]}\end{array}$ \\
\hline Round & $\begin{array}{l}-0.006 \\
(0.001) \\
{[0.000]}\end{array}$ & $\begin{array}{l}-0.020 \\
(0.003) \\
{[0.000]}\end{array}$ \\
\hline Voting Cost & $\begin{array}{l}-0.008 \\
(0.000) \\
{[0.000]}\end{array}$ & $\begin{array}{l}-0.025 \\
(0.001) \\
{[0.000]}\end{array}$ \\
\hline Constant & $\begin{array}{c}0.982 \\
(0.037) \\
{[0.000]}\end{array}$ & $\begin{array}{c}1.540 \\
(0.132) \\
{[0.000]}\end{array}$ \\
\hline $\begin{array}{l}\text { Observations } \\
R^{2}\end{array}$ & $\begin{array}{l}12480 \\
0.242 \\
\end{array}$ & 12480 \\
\hline
\end{tabular}




\subsubsection{Individual behavior: monotonicity violations and cutpoints.}

We briefly report here results on individual behavior. In cost of voting experiments, and more broadly in experiments where the equilibrium is in monotone cutpoint strategies, violations of monotonicity are informative not only about the accuracy of the theoretical predictions but also about the participants' understanding of the rules of the game. In our experiment, this is particularly important because a common objection to $\mathrm{CV}$ is that its strategic complexity is a difficult obstacle for voters. Although experimental participants limit themselves to the decision to turnout or not, the fact that under CV turnout implies casting multiple votes, and in one case fractional votes, for each candidate could indeed be confusing.

Figures A2 and A3 report histograms of the frequency of monotonicity violations by participants. For each participant, violations are counted as the minimum number of decisions that need to be modified for that participant's turnout decision to be fully monotonic in the voting cost realization: if $i$ chooses to turnout for a cost realization $c_{i}=c^{\prime}$ then $i$ should turn out for all $c_{i}<c^{\prime}$, and if $i$ chooses to abstain for a cost realization $c_{i}=c^{\prime \prime}$ then $i$ should abstain for all $c_{i}>c^{\prime \prime}$. The first bin in each histogram corresponds to no violations; the remaining bins to increasing deciles. The figures have multiple panels, for subjects in the minority (on the left) or in the majority (on the right), for different values of $K$, and for the two voting rules.

The figures establish two main results. First, monotonicity violations are not common: in all treatments and in each party, it is always the case that more than half of participants have at most a single violation (out of 15 rounds of play). The statement in fact undersells the evidence: over the full data set, 75 percent of participants have at most one violation; the corresponding shares within each party are more than three quarters (78 percent) in the majority, and more than two thirds (69 percent) in the minority. Second, and most important here, there is no systematic difference between the frequency of violations under MP and under CV: for the majority, the fraction with no more than one violation is 80 percent under $\mathrm{CV}$ and 77 under MP; for the minority, 72 percent under $\mathrm{CV}$ and 67 percent under MP. At least in the simplified structure of our experiment, the hypothesis that CV is more confusing for voters is not supported by any evidence of more random behavior. 
MPK2
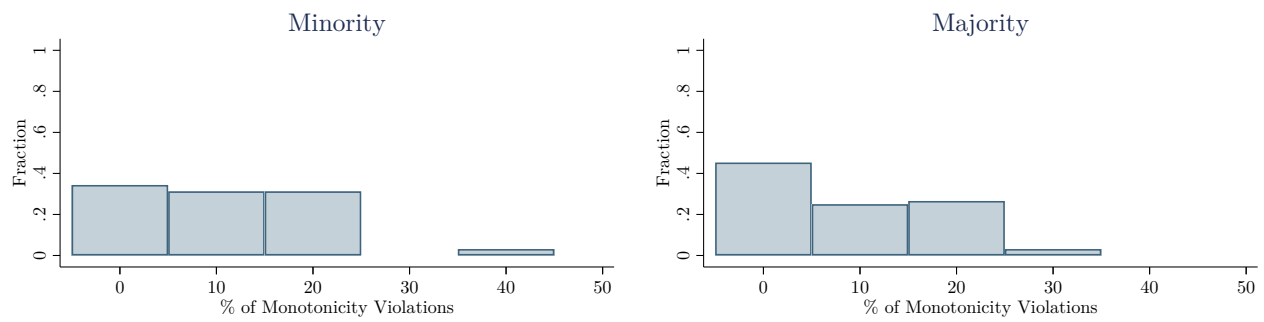

CVK2
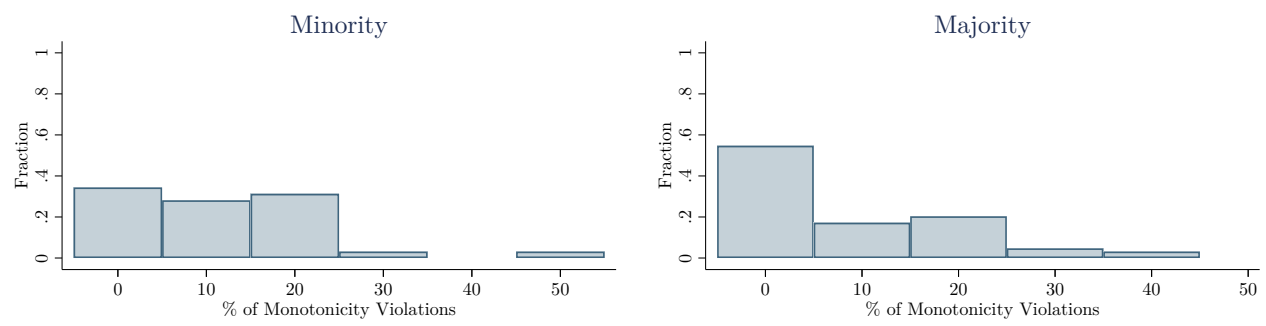

MPK4
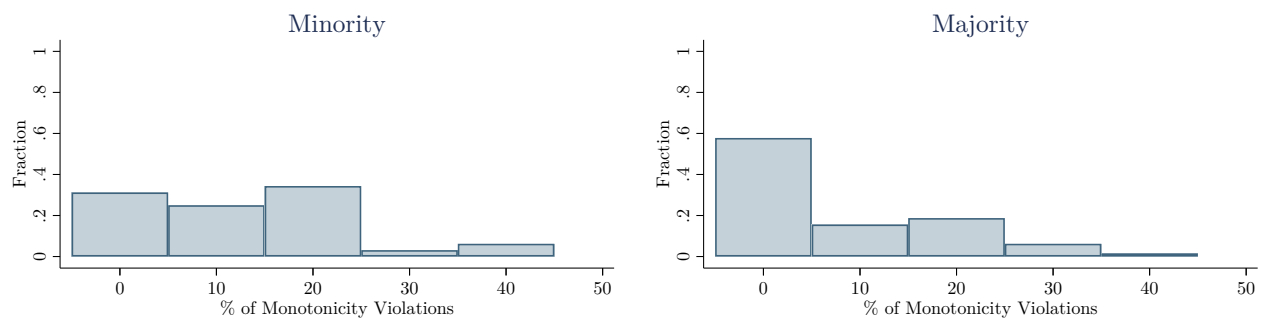

CVK4
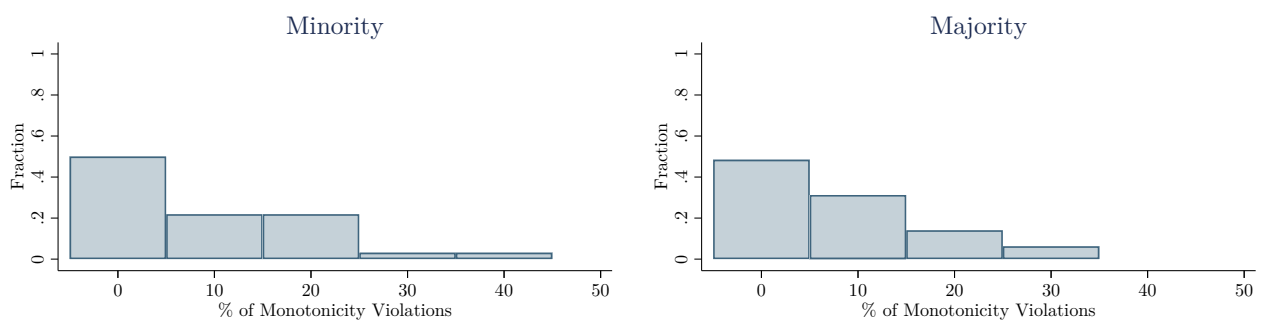

Figure A2: Monotonicity Violations $(m=2)$ 
MPK2
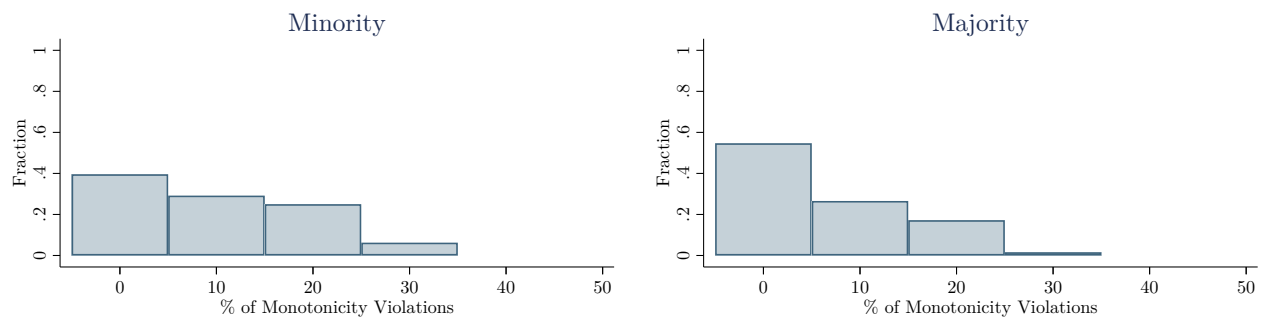

CVK2
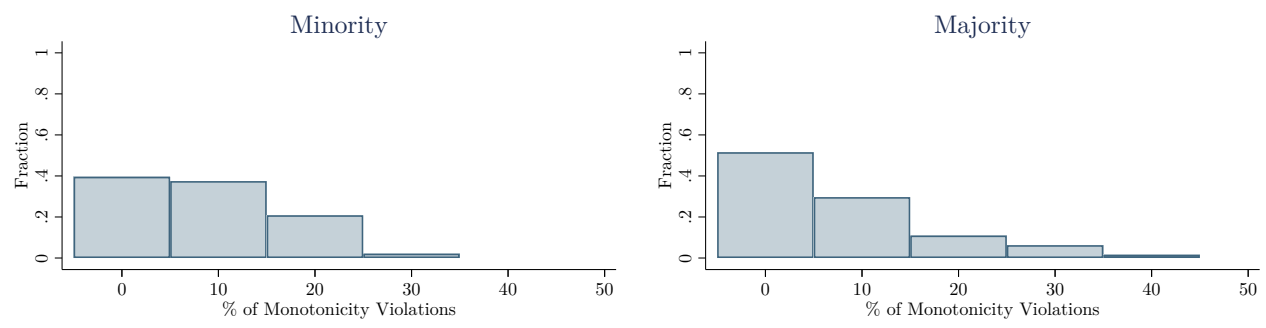

MPK4
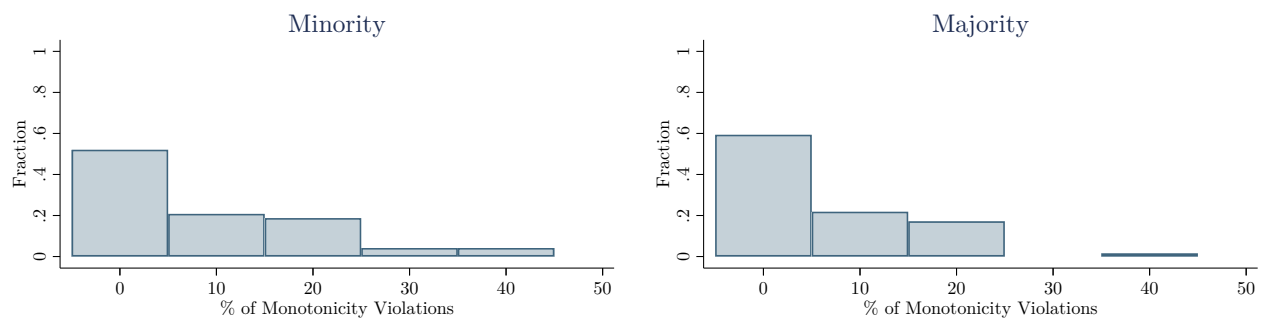

CVK4
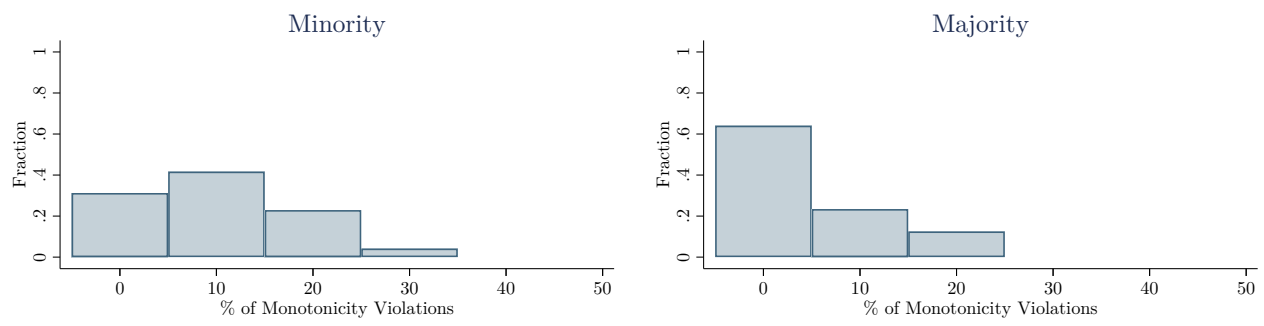

Figure A3: Monotonicity Violations $(m=3)$ 
Monotone behavior can be consistent with very different strategies, a point made very clear by Figures A4 and A5. As in other experiments where equilibrium strategies are monotonic (for example, Casella et al., 2006, Levine and Palfrey, 2007), we can use the minimization of monotonicity violations as a guide to estimating individual cost cutpoints. Figures A4 and A5 report the results of such estimation: for each subject, the figures report the cutpoint that minimizes the frequency violations. ${ }^{5}$ The blue diamonds correspond to the average of the individual cutpoints, and the grey diamond to the theoretical prediction.
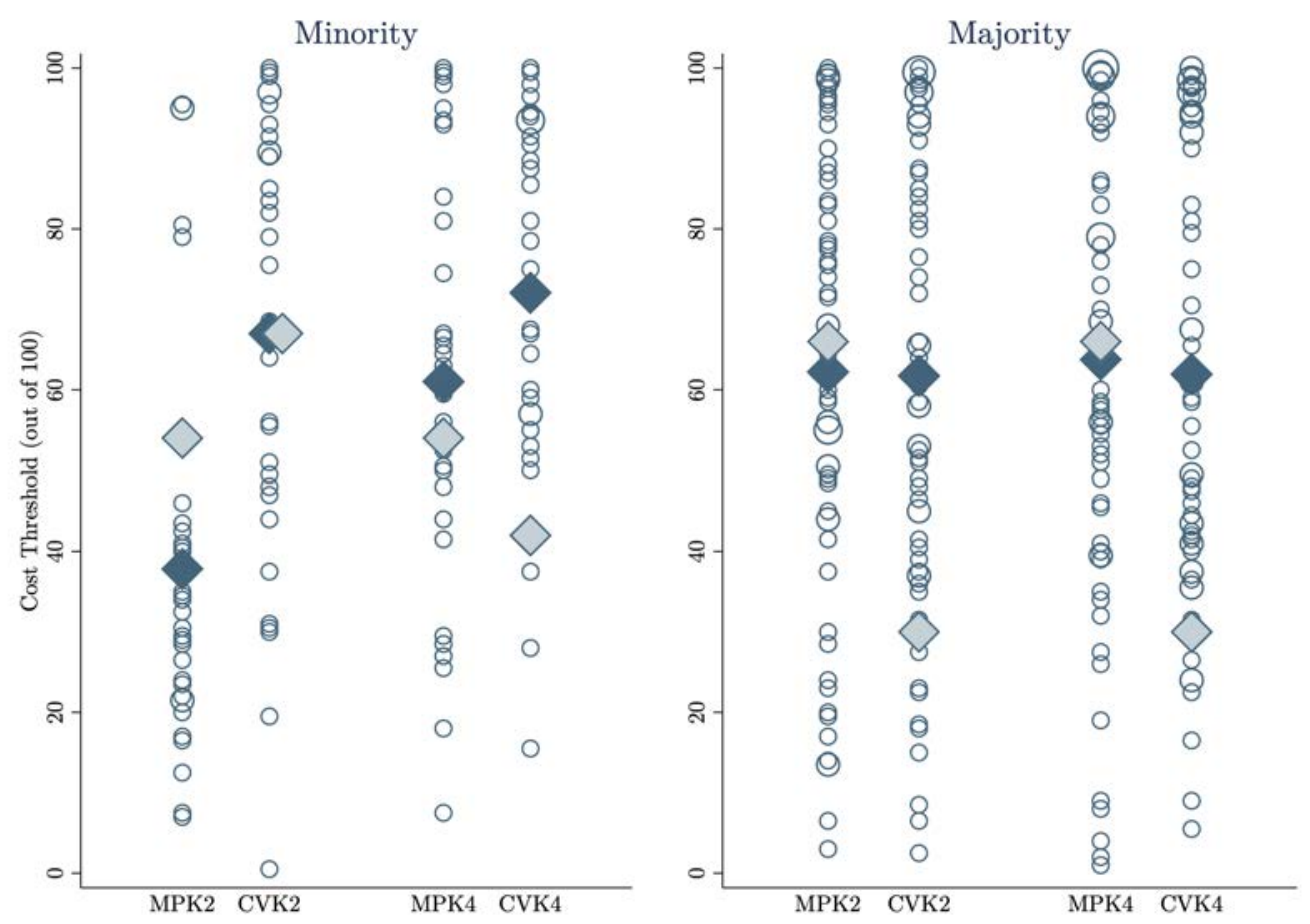

Figure A4: Cost Cutpoints $(m=2)$. The blue diamonds correspond to the average of the individual cutpoints, and the grey diamond to the theoretical prediction. The size of each circle is proportional to the number of subjects it represents.

\footnotetext{
${ }^{5}$ When, for a given subject, multiple cutpoints are consistent with minimizing monotonicity violations, the figures report the mean cutpoint. In a few cases (15 subjects out of 208), the multiplicity concerns ranges of possible cutpoints; in these cases reporting the mean would muddle behavior, and we have chosen the range that is closest to equilibrium. In all cases, we have verified that alternative choices do not change the qualitative results.
} 

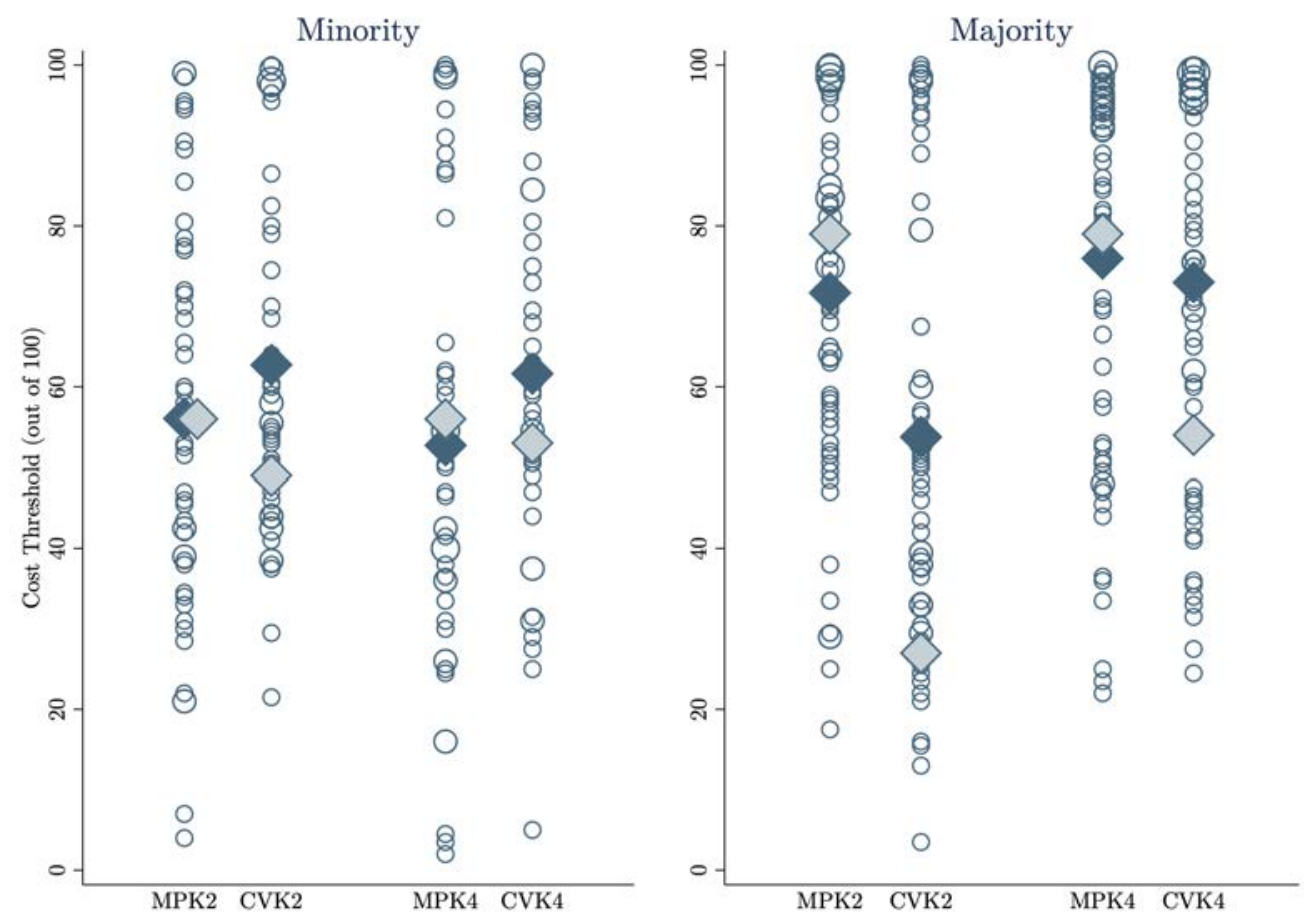

Figure A5: Cost Cutpoints $(m=3)$. The blue diamonds correspond to the average of the individual cutpoints, and the grey diamond to the theoretical prediction. The size of each circle is proportional to the number of subjects it represents.

The first observation, already noted when discussing Figure 3 in the text, is the high heterogeneity in behavior. While the theoretical semi-symmetric equilibrium predicts a single cutpoint for each party, the data show large variation in behavior, in both parties and for both voting rules. Not surprisingly, average cutpoints are closer to the theory. Second, again in line with the discussion of turnout in the text, the figures show that for both $m=2$ and $m=3$, majority subjects, on average, are less sensitive to changes in treatments than theory suggests: the range spanned by the blue diamonds is narrower than the range spanned by the grey diamonds. In particular, relative to the theory, majority subjects on average under-vote under MP and over-vote under CV, a behavior that translates into the approximate constancy of the majority turnout rate across the two voting rules.

\subsubsection{Minority Victories}

Table A4 reports the results of an OLS regression of the share of minority victories on the same regressors used earlier-dummies for the treatment parameters and CV, and their cross effects, controlling for treatment order and experimental round. As usual, the excluded case 
corresponds to MP, $m=2, K=2$, and treatment order 1 . The unit of observation is the $(m+M)$-subject voting group, and standard errors are clustered at the voting group level.

Table A4: Share of Minority Victories

\begin{tabular}{|c|c|}
\hline & $\%$ Minority Seats \\
\hline $\mathrm{K}=4$ & $\begin{array}{c}0.049 \\
(0.026) \\
{[0.065]}\end{array}$ \\
\hline $\mathrm{m}=3$ & $\begin{array}{c}0.100 \\
(0.029) \\
{[0.001]}\end{array}$ \\
\hline $\mathrm{CV}$ & $\begin{array}{c}0.158 \\
(0.025) \\
{[0.000]}\end{array}$ \\
\hline$(\mathrm{K}=4) \times(m=3)$ & $\begin{array}{l}-0.122 \\
(0.040) \\
{[0.002]}\end{array}$ \\
\hline$(\mathrm{K}=4) \times C V$ & $\begin{array}{c}0.041 \\
(0.033) \\
{[0.215]}\end{array}$ \\
\hline$(\mathrm{m}=3) \times C V$ & $\begin{array}{c}0.037 \\
(0.037) \\
{[0.308]}\end{array}$ \\
\hline$(\mathrm{K}=4) \times(m=3) \times C V$ & $\begin{array}{l}-0.019 \\
(0.048) \\
{[0.695]}\end{array}$ \\
\hline Treatment order $=2$ & $\begin{array}{l}-0.012 \\
(0.016) \\
{[0.441]}\end{array}$ \\
\hline Treatment order $=3$ & $\begin{array}{c}0.011 \\
(0.016) \\
{[0.505]}\end{array}$ \\
\hline Treatment order $=4$ & $\begin{array}{c}0.021 \\
(0.017) \\
{[0.221]}\end{array}$ \\
\hline Round & $\begin{array}{c}0.001 \\
(0.001) \\
{[0.392]}\end{array}$ \\
\hline Constant & $\begin{array}{c}0.092 \\
(0.023) \\
{[0.000]}\end{array}$ \\
\hline $\begin{array}{l}\text { Observations } \\
R^{2}\end{array}$ & $\begin{array}{l}1920 \\
0.148\end{array}$ \\
\hline
\end{tabular}


The regression confirms the regularities shown by Figure 4 in the text. In particular, CV increases the share of minority victories, and does so very significantly. As expected, so does the increase in the minority size $(m=3)$. Here again there is no effect of treatment order, and neither is there a change from earlier to later rounds, reflecting the previous finding of a parallel and equally small decline in turnout for both parties as the sessions proceeded.

\section{References for Appendix A}

Casella, A., A. Gelman and T. Palfrey, 2006, "An Experimental Study of Storable Votes", Games and Economic Behavior, 57, 123-154.

Duch, M. L., Grossmann, M. R. P. and Lauer, T., 2020, "z-Tree unleashed: A novel client-integrating architecture for conducting z-Tree experiments over the Internet”, Journal of Behavioral and Experimental Finance, 28.

Herrera, H., M. Morelli and T. Palfrey, 2014, "Turnout and Power Sharing", Economic Journal, 124, F131-F162.

Krishna V. and J. Morgan, 2015, "Majority Rule and Utilitarian Welfare", American Economic Journal: Microeconomics, 7, 339-375.

Ledyard, J., 1984, "The pure theory of large two-candidate elections", Public Choice, 44, 7-41.

Levine, D., \& Palfrey, T., 2007, "The Paradox of Voter Participation? A Laboratory Study", American Political Science Review, 101, 143-158.

Taylor, C. and H. Yildirim, 2010a, "Public information and electoral bias", Games and Economic Behavior, 68, 353-375.

Taylor, C. and H. Yildirim, 2010b, "A unified analysis of rational voting with private values and group-specific costs", Games and Economic Behavior, 70, 457-471. 


\section{Appendix B: Experimental Instructions}

We report here the instructions for a representative experimental session, with $m=2$ and 12 subjects. As discussed in the text, the sessions were held via the Zoom videoconferencing software and run virtually using z-Tree unleashed (Duch et al., 2020). As a result, instructions were conveyed in more visual style than usual.

In this experiment, you are an eligible voter in an election called to fill several seats.

You will be assigned to one of two parties, either the Purple party or the Orange party.

If your party wins positions, you win points. However, voting is costly, so if you vote, you lose points.

Your decision in each round will be whether to vote or not vote.

The experiment will have 4 Parts, each with 15 rounds.

At the end of each Part, 1 round will be randomly drawn, and the points you earned in those rounds will be converted into monetary earnings.

The conversion rate from points to dollars is: 100 points $=\$ 1.50$ dollar.

Your final earnings will also include the show-up fee of $\$ 5$. 


\section{Part 1}

Part 1 consists of 15 rounds.

Each round is a new election and will develop as follows:

At the beginning of Part 1, you will be randomly assigned to a party: either Orange or Purple.

or

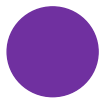

You will be part of a group of $\mathbf{6}$ voters: 2 Purple voters and 4 Orange voters. 
Your group will vote to elect a commission with 2 seats.

2 seats

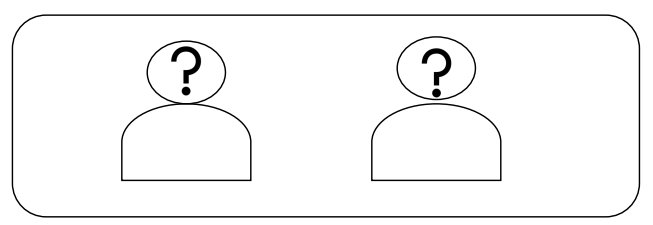

The 2 candidates with most votes win. If there is a tie, it is broken randomly by the computer.

You win $\mathbf{4 0 0}$ points if your party wins both positions, 200 points if it wins $\mathbf{1}$ position, and $\mathbf{0}$ if it wins none.

To fill these seats, the Orange party has nominated 2 candidates.

The Purple party has nominated 1 single candidate.

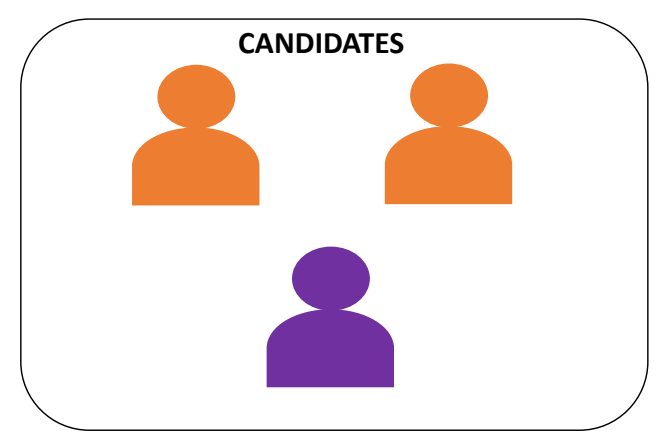


The computer screen will remind you of this information, and will look as follows.

\begin{tabular}{l}
$\begin{array}{l}\text { Your party affiliation is ORANGE. } \\
\text { This is Round } 1 . \\
\text { Your group consists of } 4 \text { Orange members and } 2 \text { Purple members. } \\
\text { You are asked to elect a committee of size 2. You have } 2 \text { votes. } \\
\text { There are } 2 \text { Orange candidates and } 1 \text { Purple candidates. } \\
\text { You win } 400 \text { points if your party wins both positions; } 200 \text { if your party wins } 1 \text { position; } \\
\text { and } 0 \text { if all positions are won by the other party. }\end{array}$ \\
\hline
\end{tabular}


Whether you are Orange or Purple, your decision is whether to vote or not vote.

You are given an endowment of $\mathbf{1 0 0}$ points. But if you vote you suffer a voting cost.

The cost is random and can be any integer between 0 and 100 with equal probability.

Your cost is independent of everyone else's cost. Thus, your cost gives you no information about their costs.

You will be shown your cost before you choose to vote or not vote.

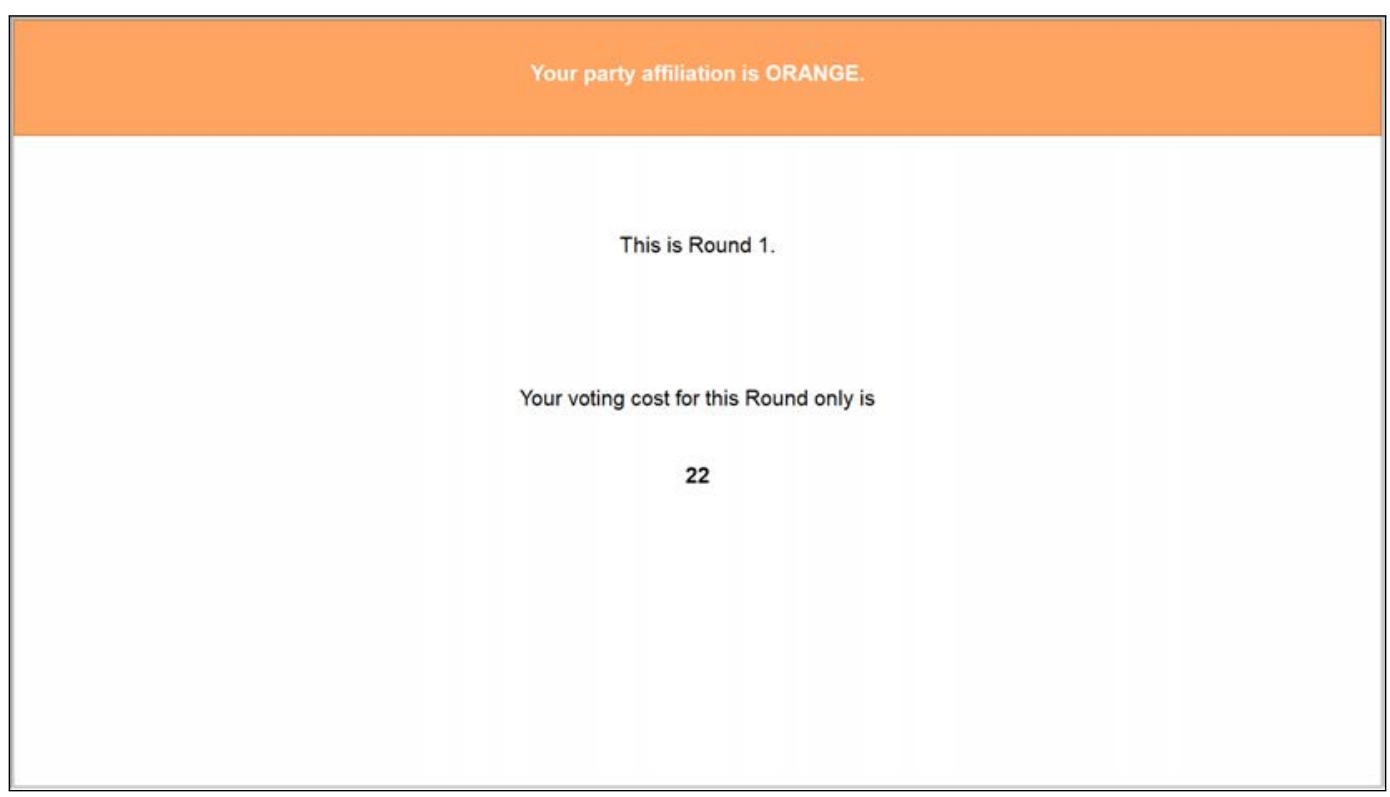


Because 2 positions are open, each voter has 2 votes.

When you vote, all your votes are shared equally by all candidates of your party.

If your party is Orange and you vote, you cast $\mathbf{1}$ vote for each of the 2 Orange candidates.

If your party is Purple and you vote, you cast both of your votes for the single Purple candidate.
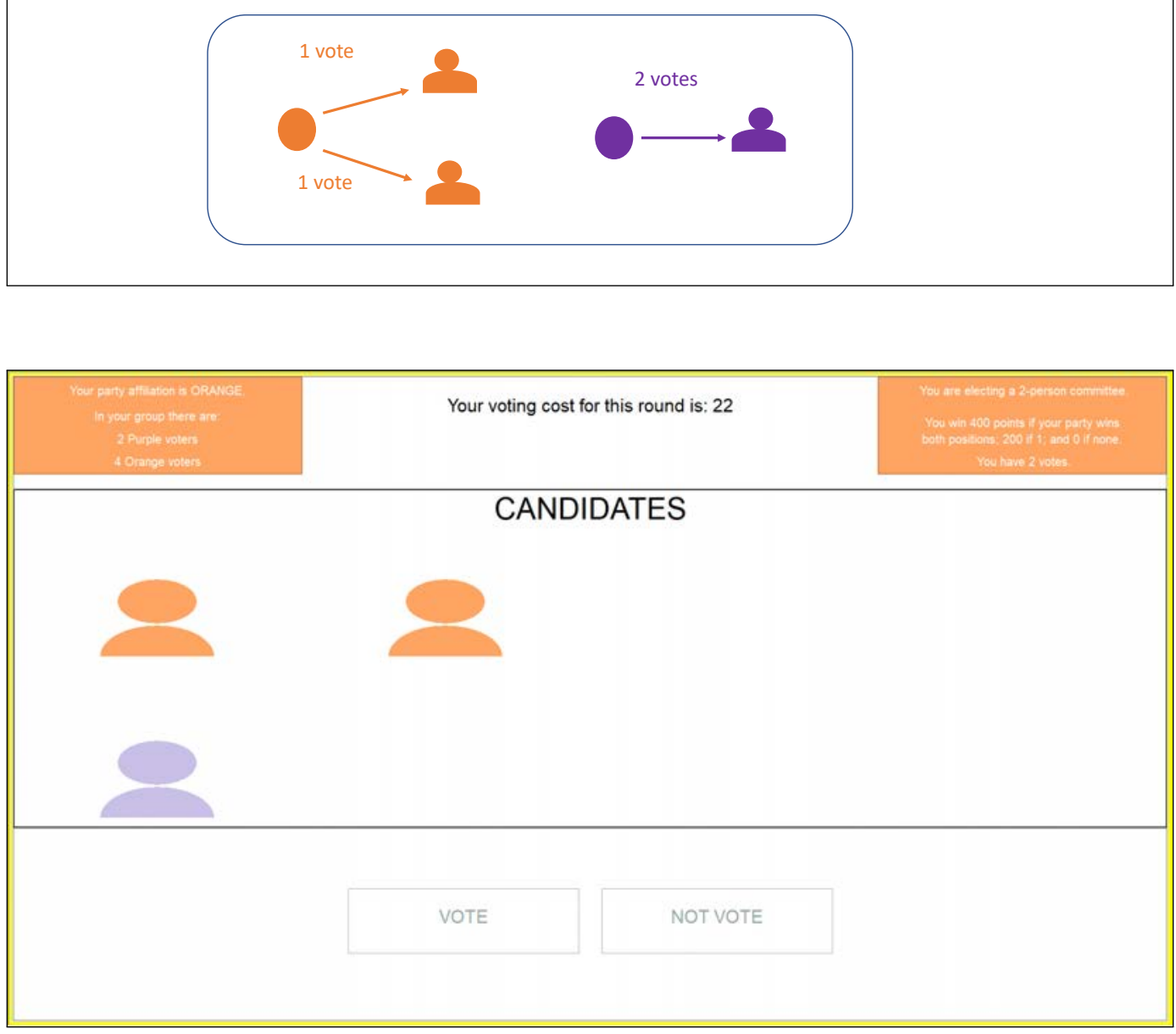


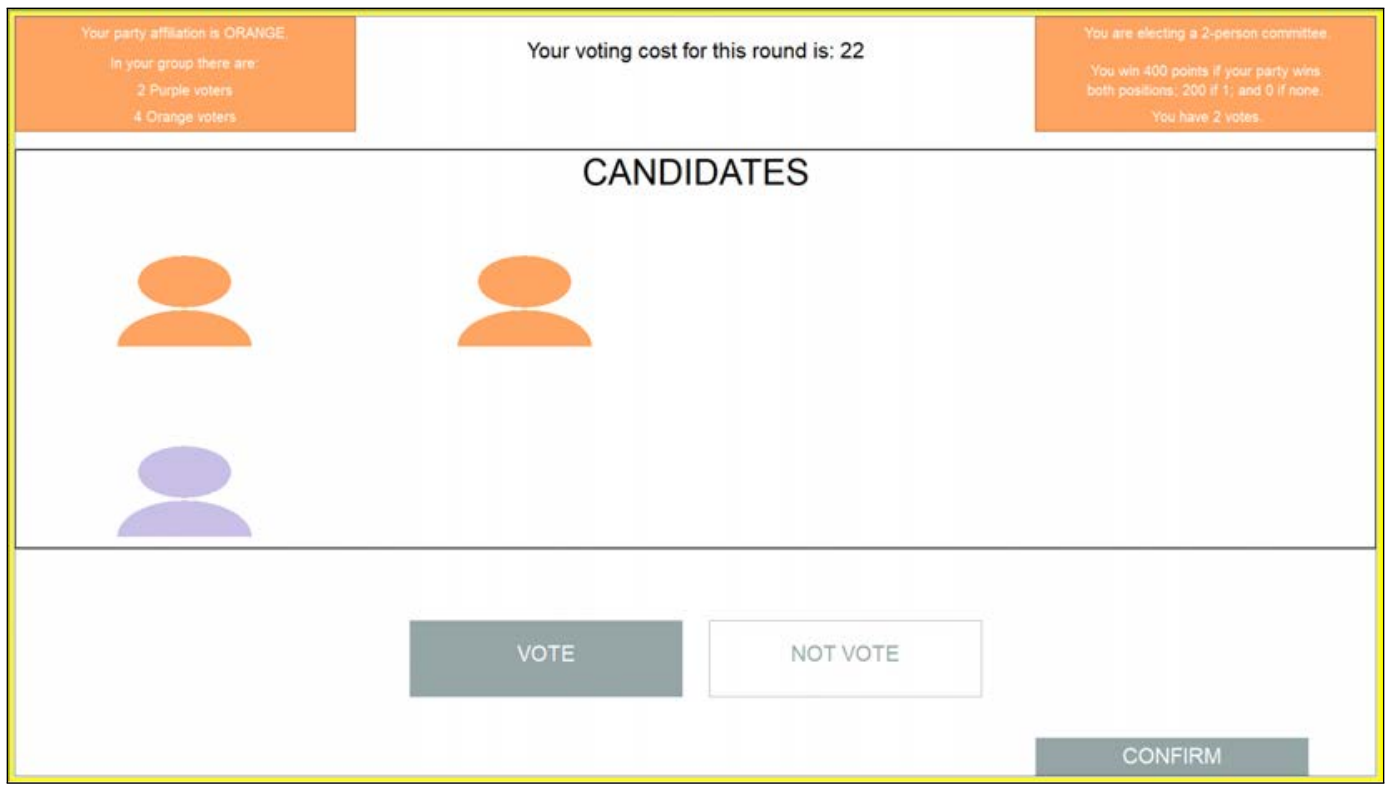

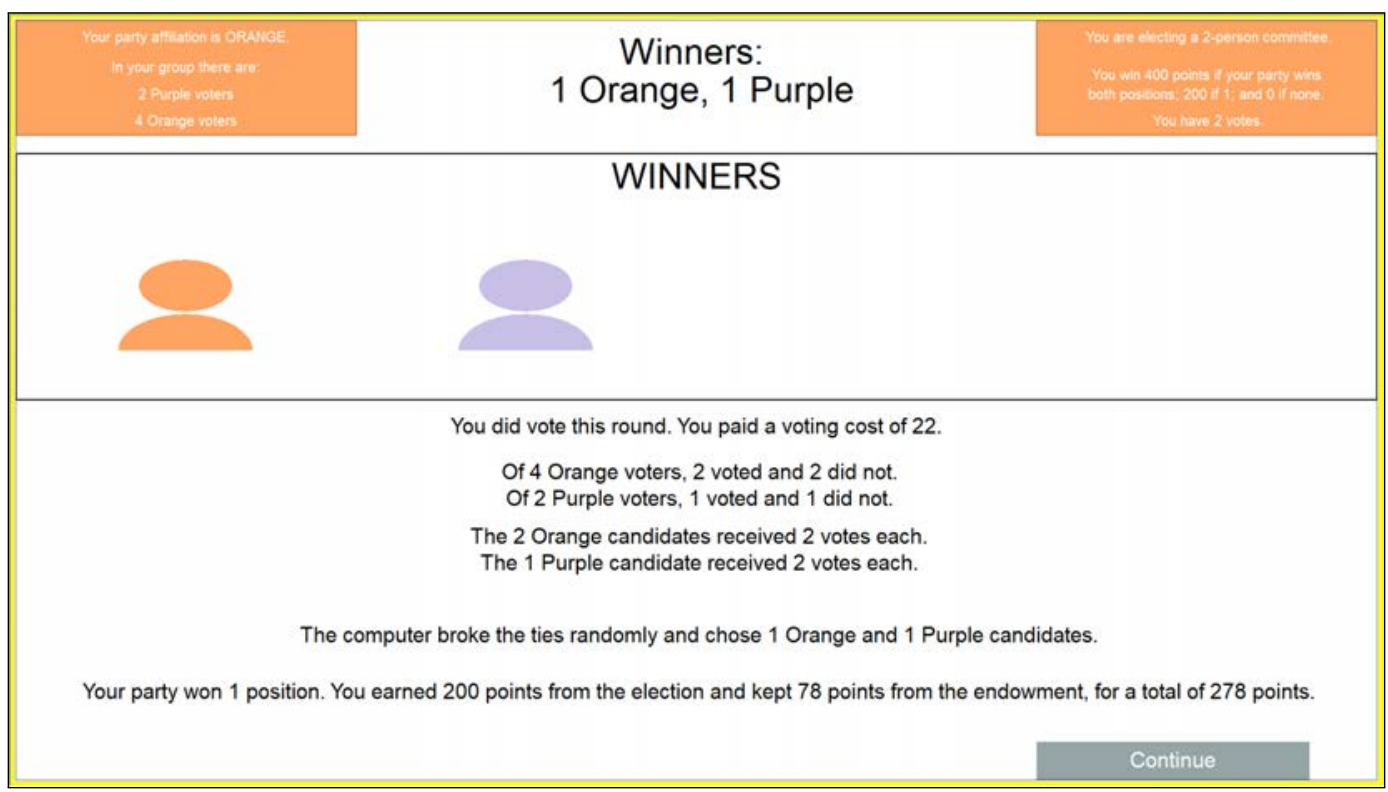


After the practice rounds, Part 1 will consist of 15 rounds.

Each round is a new election:

1. You will maintain the same party affiliation (Orange or Purple) for all of Part 1.

2. At each round, you will be rematched randomly into a group of 6 voters: 4 Orange and 2 Purple. Because groups are rematched, you will not be with the same five other subjects.
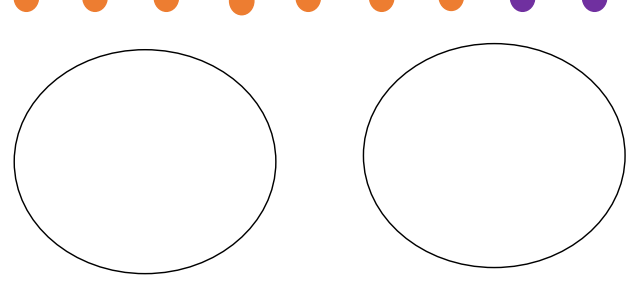

3. The groups are independent. What happens in one group does not affect the others.

4. The election will proceed as before ( 2 open seats, 2 votes per voter, 2 Orange candidates, 1 Purple candidate)

5. All random voting costs will be drawn again. Each voter will receive a new endowment of 100 points.

6. You and everyone else will decide again whether to vote or not. 


\section{SUMMARY}

Your group votes to fill $\mathbf{2}$ open seats and each voter has $\mathbf{2}$ votes.

You win 400 points if your party wins both seats, 200 if 1,0 if none.

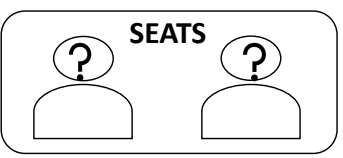

There are 2 Orange candidates and 1 Purple candidate.

voter has 2 votes, an Orange voter who votes casts 1 vote for each Orange candidate; a Purple voter who votes casts 2 votes for the single Purple candidate.

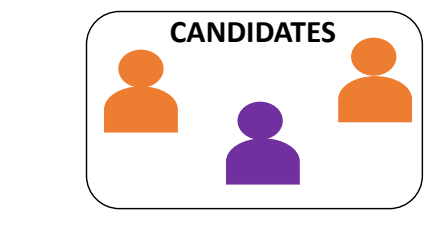

The group consists of 4 Orange voters and 2 Purple voters.

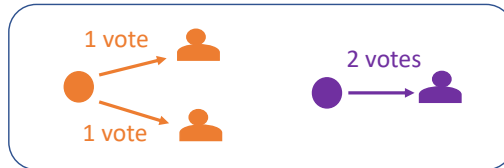

VOTERS

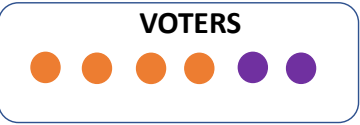

Voting is costly.

If you vote, you pay your voting cost whether or not your party wins any position.

If your party wins any position, you will receive points whether you voted or not.

Your party is more likely to win positions if you vote.

Your decision will be whether to vote or not. 


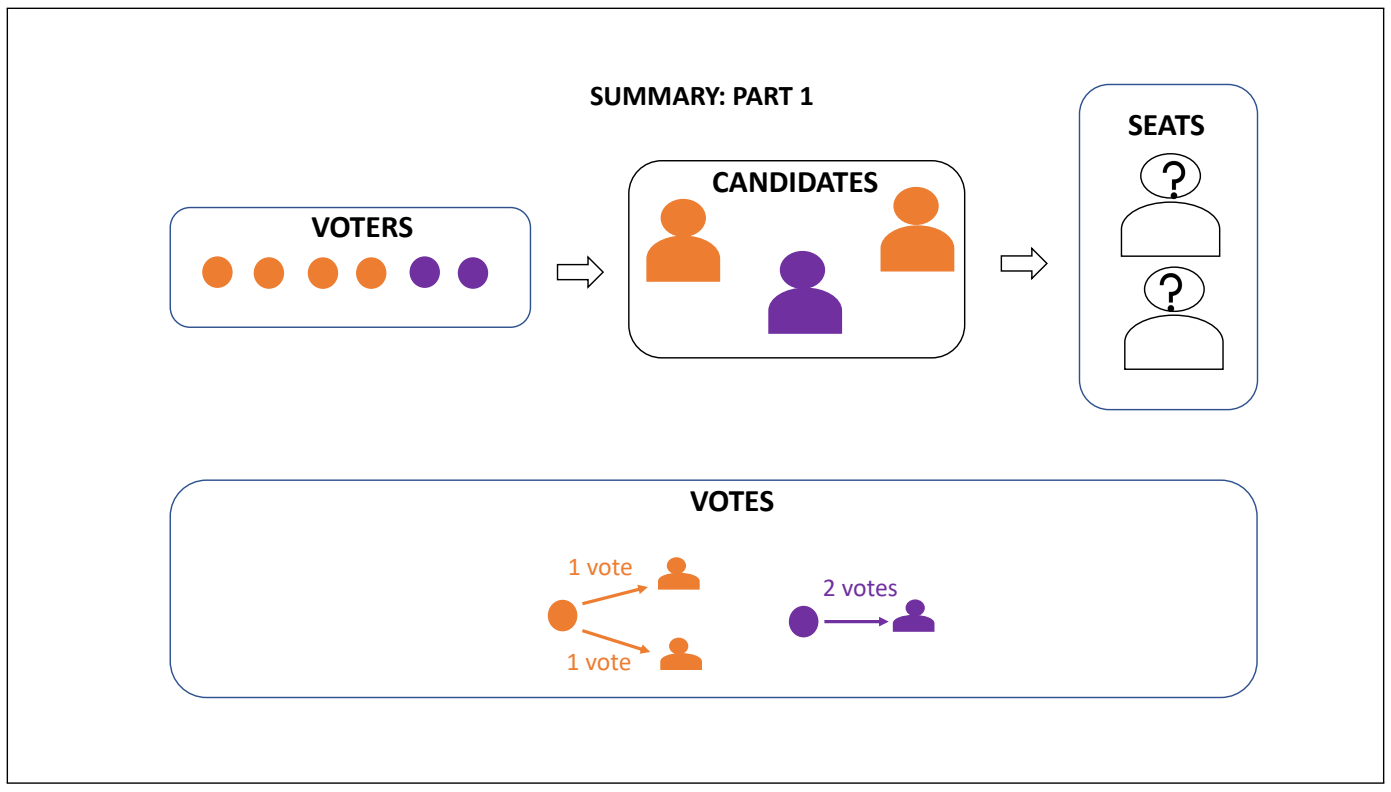

Part 2 
Part 2 is very similar to Part 1.

The difference is in the number of candidates:

In part 2, both parties have nominated $\mathbf{2}$ candidates each.

If you vote, you cast 1 vote for each of your party's candidates.

The two winning candidates will be the two candidates with most votes, as before.

You will be randomly reassigned a party affiliation, either Purple or Orange, which may differ from Part 1 and that you will keep for the whole of Part 2.

Everything else remains identical.

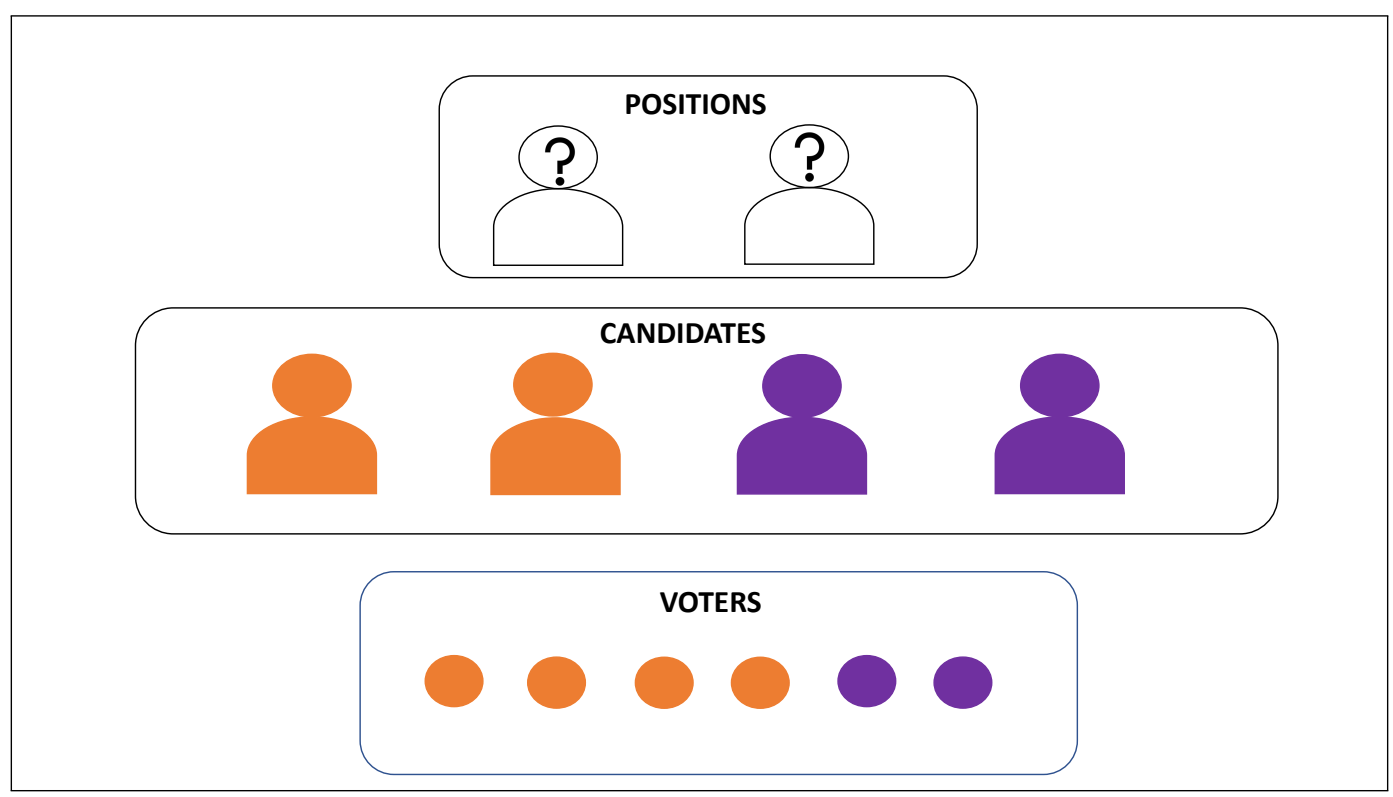




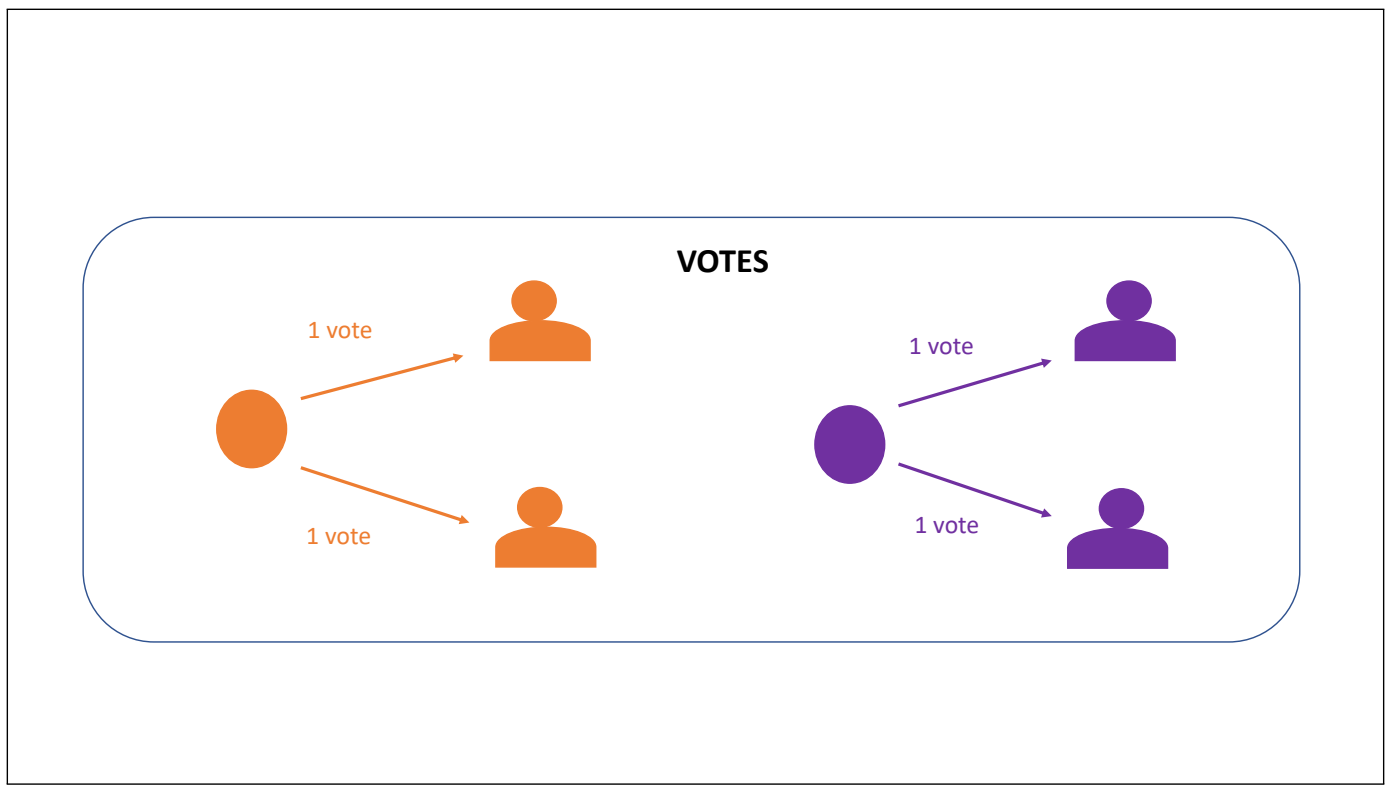

Part 2 will last 15 rounds.

Remember that:

- groups are reshuffled at each round.

- voting costs are redrawn at each round. 


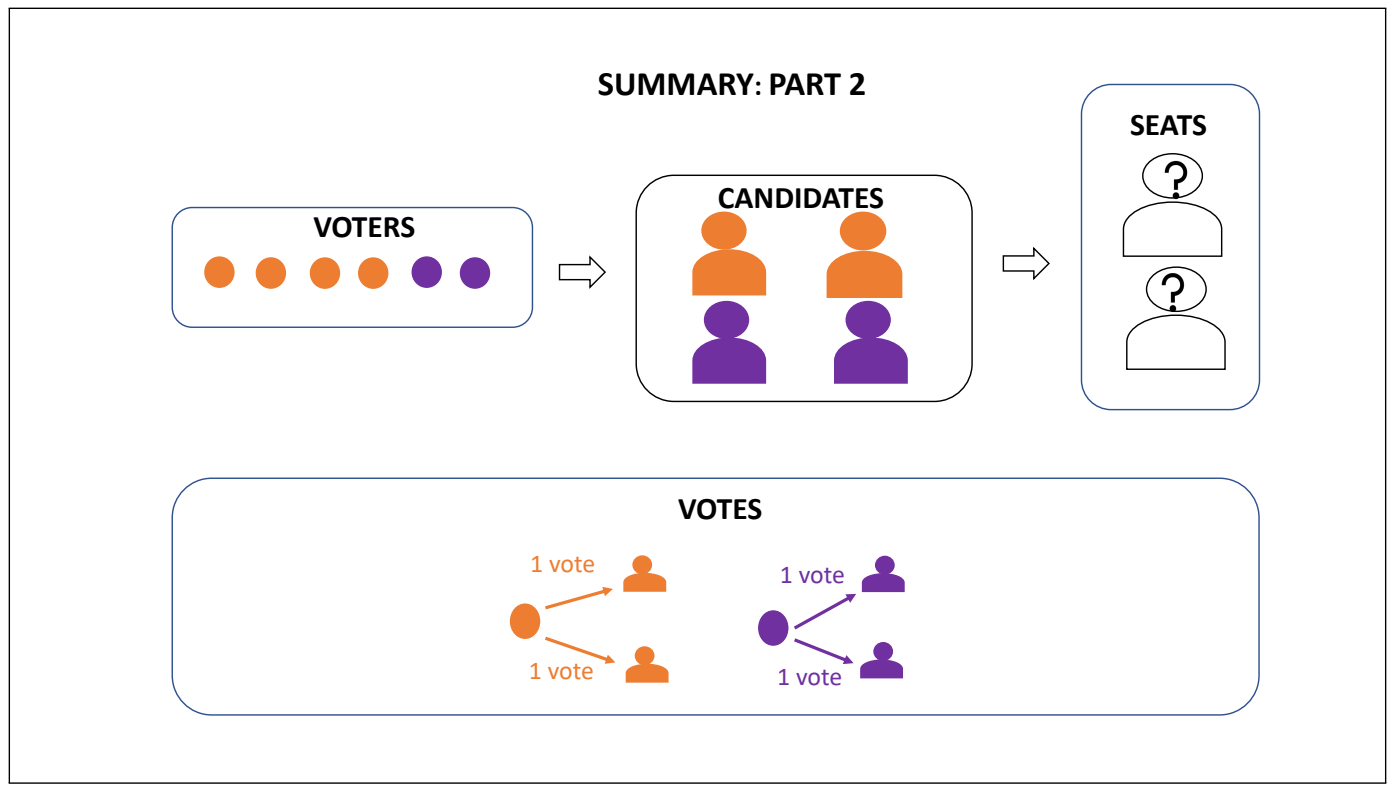

Part 3 
Part 3 is very similar to Part 2.

There are three differences:

1. In Part 3, your group will elect a 4-person commission: the election is for 4 open seats.

2. Each voter has $\mathbf{4}$ votes.

3. Each party has nominated $\mathbf{4}$ candidates.

If you vote, you cast 1 vote for each of your party's candidates.

The 4 winning candidates will be the 4 candidates with most votes.

In addition to the 100 points round endowment, you win 400 points if your party wins 4 positions, 300 if it wins 3, 200 if 2, 100 if 1 , and 0 if it wins none. 

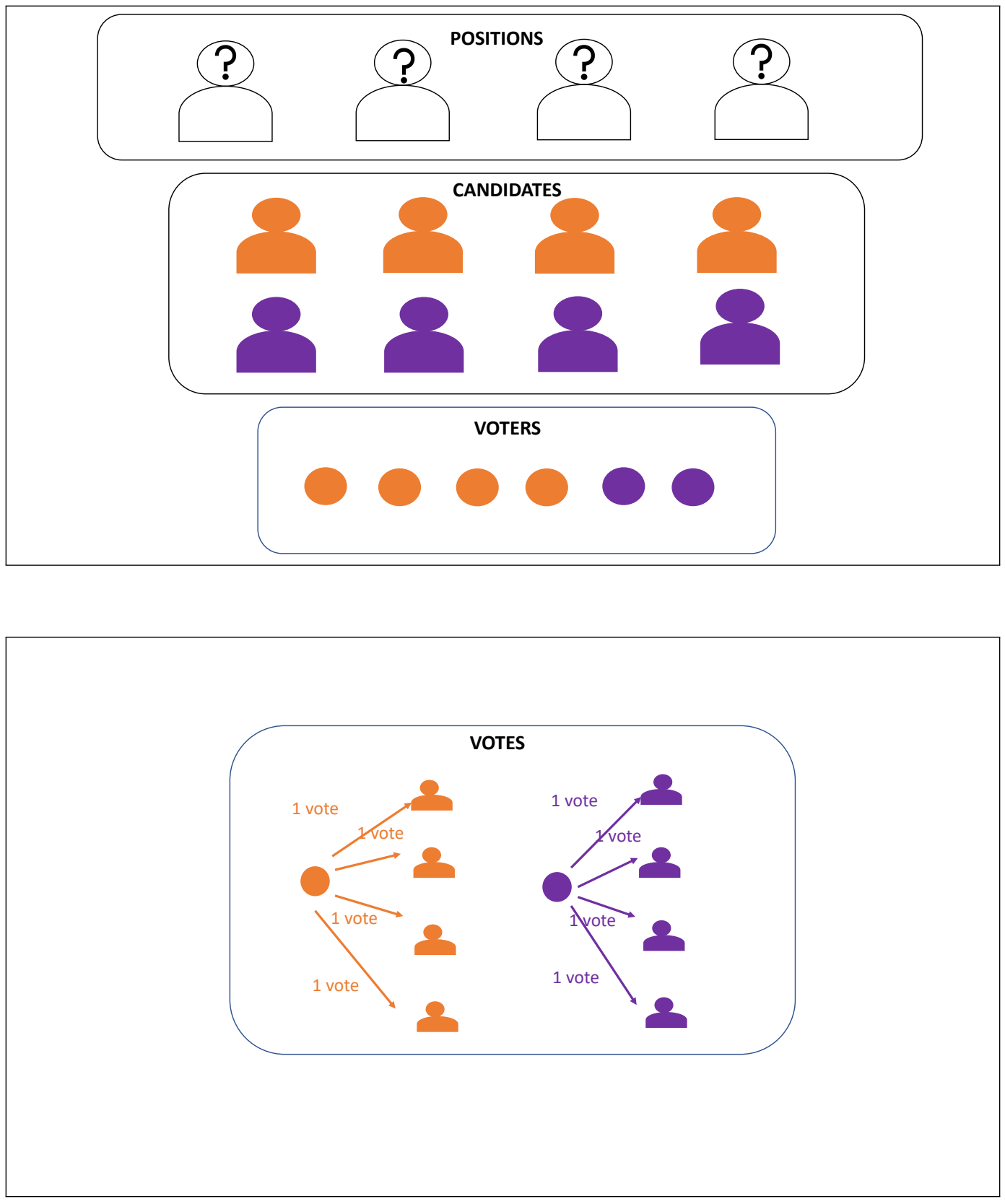
You will be randomly reassigned a party affiliation, either Purple or Orange, which may differ from Part 2 and that you will keep for the whole of Part 3.

Everything else remains identical.

Part 3 will last 15 rounds.

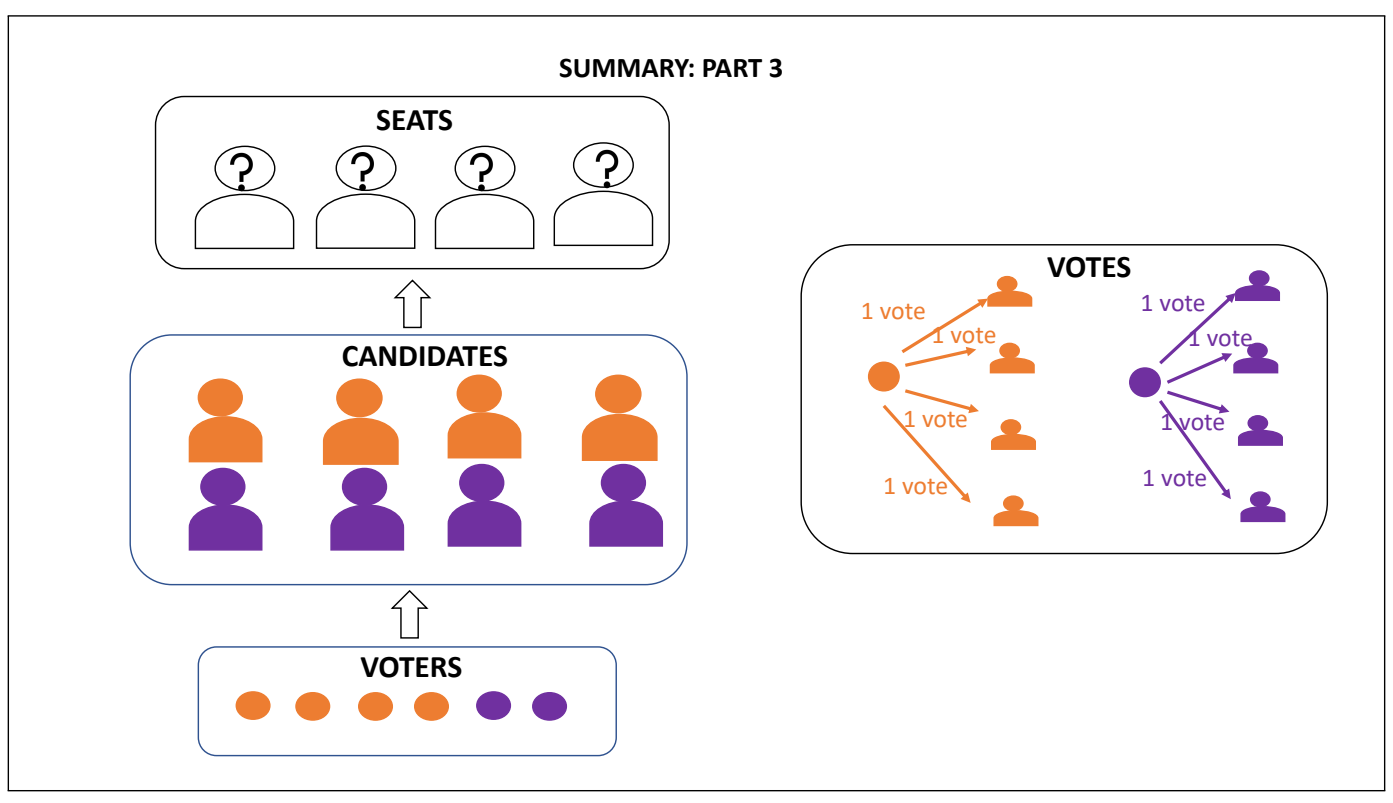




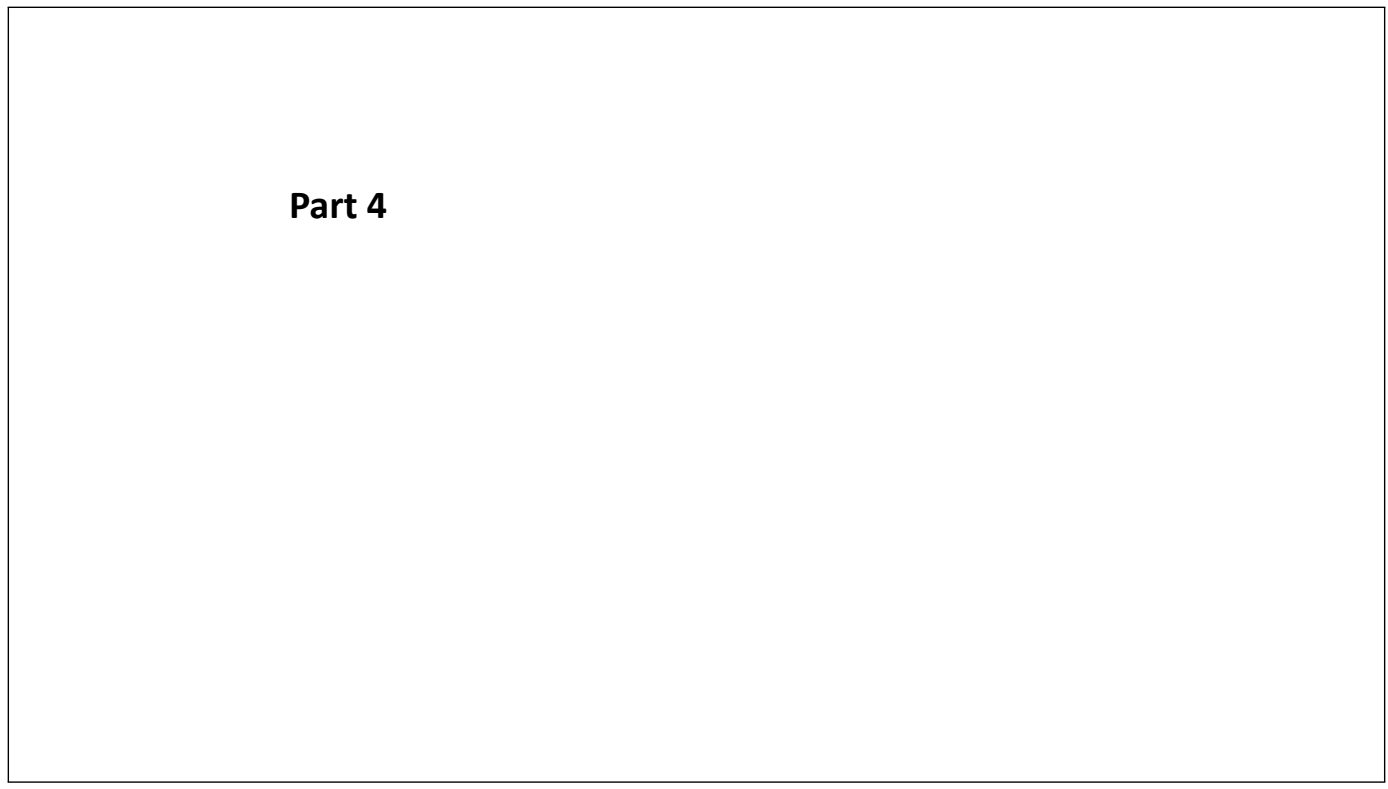

Part 4 is very similar to Part 3.

The difference is in the number of candidates:

The Orange party has nominated 3 candidates.

The Purple party has nominated 2 candidates.

Because every voter has 4 votes:

If you vote and are Orange, you cast 4/3 votes for each Orange candidate.

If you vote and are Purple, you cast 2 votes for each Purple candidate.

The 4 winning candidates will be the 4 candidates with most votes, as before. 

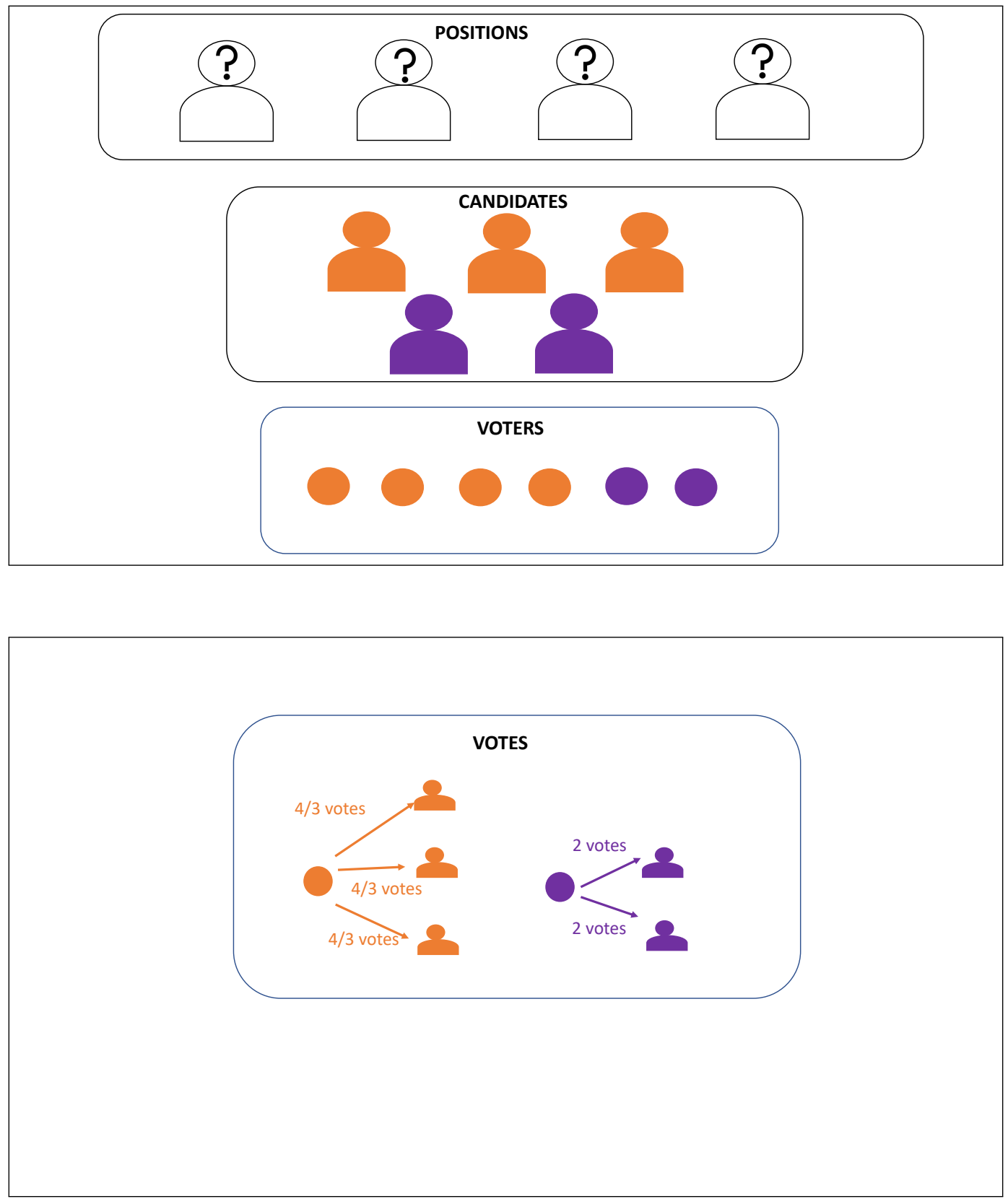
You will be randomly reassigned a party affiliation, either Purple or Orange, which may differ from Part 3 and that you will keep for the whole of Part 4.

Everything else remains identical.

Part 4 will last 15 rounds.

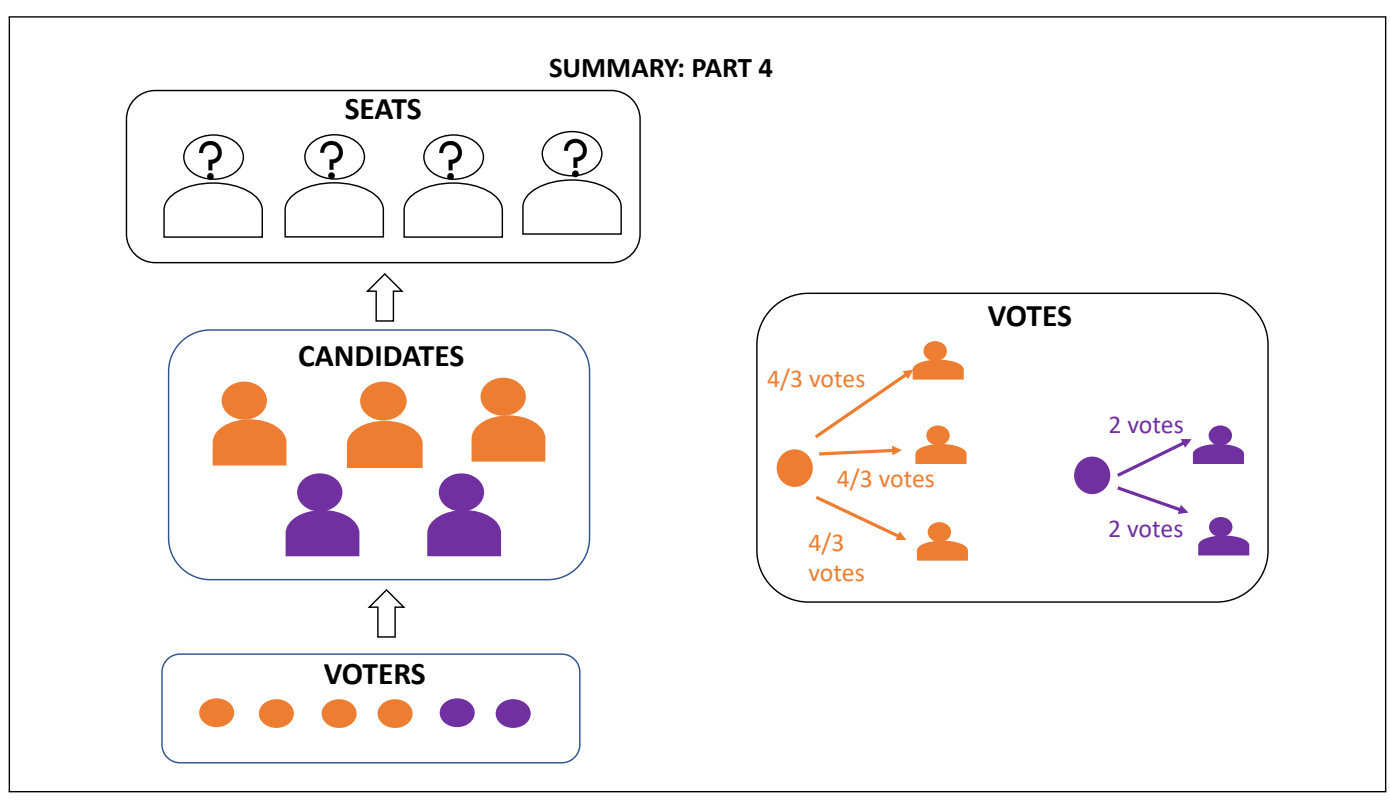

